\title{
YOUNG DIASPORA SOMALI WOMEN'S NAVIGATION OF INTERSECTIONAL IDENTITIES IN ONLINE SOCIAL MEDIA SPACES
}

\author{
by \\ Samira Warsame \\ B.A. (Double Major, International Development Studies and City Studies) \\ University of Toronto, 2017 \\ A Major Research Paper \\ presented to Ryerson University \\ in partial fulfillment of the requirement for the degree of \\ Master of Arts \\ in the program of \\ Immigration and Settlement Studies
}

Toronto, Ontario, Canada, 2019

(C)Samira Warsame, 2019 


\section{AUTHOR'S DECLARATION FOR THE ELECTRONIC SUBMISSIONS OF A MAJOR RESEARCH PAPER (MRP)}

I hereby declare that I am the sole author of this Major Research Paper. This is a true copy of the MRP, including any required final revisions.

I authorize Ryerson University to lend this MRP to other institutions or individuals for the purpose of scholarly research.

I further authorize Ryerson University to reproduce this MRP by photocopying or by other means, in total or in part, at the request of other institutions or individuals for the purpose of scholarly research.

I understand that my MRP may be made electronically available to the public.

Samira Warsame 


\title{
YOUNG DIASPORA SOMALI WOMEN'S NAVIGATION OF INTERSECTIONAL IDENTITIES IN ONLINE SOCIAL MEDIA SPACES
}

\author{
Samira Warsame \\ Master of Arts, 2019 \\ Immigration and Settlement Studies \\ Ryerson University
}

\begin{abstract}
Using Crenshaw's work on intersectionality, this research examines how young Somali women have used the arts to challenge negative mainstream media discourse regarding the Black, Muslim and Somali identities. This research, similar to Crichlow's work on narrative sharing in the classroom space being used to amplify the voice of the oppressed and the marginalized, finds that young Somali women are using the arts interact with their intersectional identities and share them in online spaces. Social media has provided room for them to use and amplify their own voices which inevitably challenges negative representations promoted by mainstream media outlets while interacting with their intersectional identities. Using 6 Somali women from the arts communities in two of the major Somali-populated cities in the West; Toronto, Canada, and Minneapolis, USA, this work explores how young Somali women artists have been able to critically and creatively shape a more nuanced discourse about their identities.
\end{abstract}

\section{Keywords:}

Diaspora youth, Black AND Muslim, Somali women, arts-based inquiry, belonging, social media, narrative sharing, resiliency. 


\section{Acknowledgements}

I would like to first thank Al-Waduud (The Most Loving) and Al-Mughni (The Enricher/Emancipator). You opened doors for me, and lit a fire in me that wouldn't go out till I achieved my goals. For I would be nothing without You, Allah, and all of the blessings You have bestowed on me. Alhamdullilah

My parents, Hooyo and Aabo, the loves of my life. Your journey to Canada was not one that was easy. Leaving your home was not easy. Settling somewhere new was not easy. But just know that your children appreciate you, Alhamdullilah. Allah blessed us with the most resilient parents. Whatever you lost during your journey to this land, I pray you gain it back a million times over in Jannah. It was you who supported me and have provided me with the tools I needed to be able to succeed and be the strong woman I needed to be for this. Thank you <3

I'd also like to thank all of my siblings and chosen family, who have held me down for throughout the stressful all-nighters and anxiety and being patient with me when I'd pull out my laptop to write/edit even while travelling. I'll love you forever.

Thank you to the resilient Somali women who participated in this study. Allah gave me the most amazing and talented women to interview and this research would not have been possible without them!

I'd also like to thank my mentors Hawa Mire and Hibaq Gelle, without them, I wouldn't have started my photography series, Search For Hooyo, which was my main inspiration for this research. You both will always be in my heart.

I'd also like to give my thanks to my supervisor, Professor Amina Jamal, who was so motivating and supportive throughout this entire writing process. My thanks also goes to Professor Nicole Neverson who agreed to be my second reader, your feedback is much appreciated. 


\section{Dedication:}

This research is for the young diaspora. This research is for the children of refugees. This research is for young Somalis. This for all of us who are resisting and reshaping the mainstream narrative by speaking our truths and holding our heads high, whether in public or in private. I support you in all the work you are doing to feel safe and feel a sense of belonging.

I was wrapping up this paper throughout the month of July, 2019. A month when Toronto and the wider Somali community lost a woman who worked to uplift young Somalis and reshape the negative stereotypes of the Somali people. Hodan Nalayeh, I would have loved for you to read this paper. May Allah grant you and your husband the highest level of Jannah $<3$ 
Authors Declaration

Abstract

Acknowledgements

Dedication:

Chapter 1: Introduction

1.i. Operational Definitions 3

Chapter 2: Personal Standpoint 5

$\begin{array}{ll}\text { Chapter 3: Research Questions } & 7\end{array}$

$\begin{array}{ll}\text { Chapter 4: Voices of Literature } & 7\end{array}$

4.i. Discourse on Black, Muslim Women and Belonging in the West 8

4.i.a. Black/African women and Belonging in Canada/U.S. $\quad 8$

4.i.b. Muslim women and Belonging in Canada/USA 9

4. ii. Role of Media on the Sense of Belonging 13

4.ii.a. Black women in mass media vs. social media 14

4.ii.b. Muslim Women in Mass Media vs. Social Media 17

4.iii. Discourse on Somalis in the West 19

Chapter 5: Theoretical Framework 22

5.i. Intersectionality 23

5. ii. Homi Bhabha Third Space 25

5.iii. Hall's discourse on media representation 27

Chapter 6: Methodology 30

6.i. Method: Arts-Based Qualitative Research; In-Depth Interviewing 30

6.ii. Sample - Participants 33

6.iii. Procedure: Data Collection and Analysis

6.iv. Strengths and Limitations 36

Chapter 7: Findings and Analysis 37

7.i. Spaces of (Un)Belonging 38

7.ii. Lack of Representation and Misrepresentation 42

7.iii. Agency in Storytelling 44

7.iv. Challenging and Disrupting the Mainstream 46 
7.v. Third Space and Resiliency 48

Chapter 8: Discussion and Conclusion 51

Chapter 9: Recommendations and Further Studies 54

Appendices $\quad 56$

A.1. - Consent Form

A.2. - Recruitment Poster $\quad 59$

$\begin{array}{ll}\text { A.3. - Interview Guide } & 60\end{array}$

$\begin{array}{lc}\text { References } & 61\end{array}$ 


\section{Chapter 1: Introduction}

"The truth about stories is, that's all we are."

- Thomas King (King, 2011, p.2)

"Identity" and "belonging" are concepts often used in analysis of contemporary society, particularly in addressing the settlement and integration of immigrant communities. Unfortunately, contemporary academia makes little mention of the experiences of belonging of the Somali community in both Toronto, Canada and Minneapolis, United States of America (U.S.) in respect to the societies they reside in. Identity is conceptualized and understood through the experiences and interactions an individual has within their environments and can play a determining factor in how one situates themselves in society (Hall, 1992). Hodan A. Mohamed interestingly conceptualizes the racialization of the Somali individual as being "at a crossroads between Orientalism and Africanism" where they are framed under the stereotypes of being an Orient or Muslim in juxtaposition of the Western identity, and where their African identity places them within the stereotypical image of being "primitive and subhuman" (Mohamed, 2017, p.11). Intersectionality, coined by Kimberle Crenshaw, is a framework of understanding that shared identities do not create homogenous experiences (Crenshaw, 2016). Developed during feminist movements, it was used to explain the phenomena in which the fight for women's rights did not always include women of color or that the fight for Black lives, did not necessarily include Black women (Crenshaw, 2016). The intersectionality framework applies across all identities, where the issues of some are prioritized over the issues of others (Collins \& Bilge, 2016). For example, not all Muslims experience the same type of Islamophobia; gender, immigration status, visibility as a Muslim (i.e., head coverings and grown out beards), and race 
all play a role in the experience of Islamophobia as well. Online social media spaces such as Twitter and Instagram, have been spaces of interactions and dialogue among diaspora communities in the West where issues of intersectionality and identity are openly addressed and discussed. Social media has been a key site in identity negotiation as well as in the formation of online communities where these conversations can be openly had around shared histories of music, culture and language, as well as colonialism, war and displacement (Mainsah, 2014). It is these "digital diasporas" that have created a means for the young diaspora population to find a sense of belonging in the online world; young Somali women in particular have been carving out spaces for themselves where society has failed to do so in face-to-face societal spaces (Mainsah, 2014). With mainstream media playing a critical role in the formation of mainly negative discourse surrounding marginalized identities, there is room to delve into the nuanced experiences this marginalization causes (Jiwani, 2018), (McMurray, 2007). It is with this understanding of mainstream media as a tool for negative representation of marginalized identities and social media as a means of diaspora connection, that the Somali artist community will be examined to better understand their sense of belonging and the ways in which they challenge mainstream narratives.

\section{Somalis Initial Interaction with the West}

Residing at the intersections of being Black, Muslim women and holding precarious refugees/immigrant statuses, Somali women, upon arrival to Canada and the U.S. were ostracized, marginalized and stereotyped with little social services provided to the community to ensure the safe and full integration into Canadian and American societies (Shephard, 2018). The introduction of Somalis to the West was not one that was welcoming, nor open armed. As a 
nomadic group of people, Somali migration to both Toronto and Minneapolis was based on word of mouth. Once safety was insured, refugees who had arrived in Toronto and Minneapolis, and many other cities around the world began to call their friends and families who were also escaping the war to advise them of this safe haven they have found, leading to large numbers of refugees settling in Toronto and Minneapolis. The mass influx of Somali refugees into Canada and the U.S. 25-30 years ago due to civil unrest and mass killings in Somalia, proved to be one that neither Canada nor the U.S. was prepared for (Berns-McGown, 1999). Unlike the U.K., where the Somali community had long since been established, Toronto, Canada and Minneapolis, U.S., were ill-equipped to support the settlement and integration of this large population of refugees (Berns-McGown, 1999). The relationship between Canada and Somali refugees started off rocky, with a sudden increase of policy restrictions on refugee arrivals into Canada beginning around the 1990's, there seemed to be a strong aversion into allowing Somalis to settle in Canada. One of the first instances of Somalis being represented in Canadian media was in March, 1993 (Foot, 2018). While Canadian soldiers were on a peacekeeping mission in Somalia, an incident known as the "Somali affair" took place in which a young 16-year-old Somali boy, Shidane Arone, was tortured and then beaten to death with a telephone book by Canadian soldiers for attempting to steal food inside an IDP camp (Foot, 2018). Upon committing these heinous crimes, the Canadian soldiers then proceeded to take photos with the young boy's deceased body, which somehow got into the hands of Canadian media and tarnished the name of Canada as a nation of peace for years to come (Foot, 2018). Shortly after this scandal, many more Somalis were accepted into Canada as refugees than in previous years (Berns-McGown, 1999), potentially as a way for Canada to rectify its wrongdoings in the 
international community. The following years were formative in the ways in which Somalis understood their identity and their sense of belonging in Canada and the United States.

\section{1. i. Operational Definitions}

Throughout this study, "Black" and "African diaspora" will be used simultaneously and interchangeably to describe the identities Somalis inherited upon arriving in the West. Prior to their escape from their homelands, Somalis mainly identified with their clans and subclans and it was only when they arrived in the West, like many African immigrants, they inherited experiences of "Blackness" which was accompanied by societal and economic barriers based on racial discrimination.

Additionally, "cultural hybridity" will be used to address instances of the ethnic Somali identity fusing with the national identity of the participants. This term, coined by Homi Bhabha, will be used in a post-colonial sense that is representative of the resiliency of the individuals practicing aspects of both their home ${ }^{1}$ and adopted ${ }^{2}$ cultures, rather than placing one culture as dominant above the other (Bhabha, 1994). Somalis, historically, are a nomadic people whose lives revolved around relocating to where the Earth would be able to sustain themselves and their families, and there was a resiliency in never calling any particular place home (Tusi, et al. 1991). The displacement of Somalis into the West with the intention of providing safety and stability for themselves and their families, meant that the initial refugees did not have time to integrate, only to survive. Their children however, the main subjects of this research, despite residing in a nation of systemic anti-Blackness and Islamophobia, have the opportunity to resiliently live and practice both their home culture and their adopted cultures. While acknowledging that there are

\footnotetext{
${ }^{1}$ The culture of the home that immigrants emigrated from, or in the case of the children of refugees, the homes of their parents.

2 The culture of the land they are currently residing in.
} 
systemic anti-Black and Islamophobic barriers to the ways in which cultures, religions are practiced in the West, young Somali's have resiliently attempted to straddle all of their identities or align with some over others, whether it is their culture, race, religion, gender, sexuality, etc. It is with this understanding of "cultural hybridity" that I will be examining the experiences of young Somali women in both Toronto and Minneapolis.

\section{Chapter 2: Personal Standpoint}

My positionality was a major source of motivation for the pursuing of this study. As a daughter of a Yemeni mother and Somali father, both of whom escaped the civil war in Somalia together in 1989 with my two eldest siblings, my life has centered around building an understanding and foundation of where I belong. Although my parents had been in Canada for five years by the time I was born, and despite them having two other children born in Canada prior to my arrival, my parents were still dealing with issues around their refugee status. My father's refugee status had been denied, under the assumption that his clan was not being targeted during the war, and it was a long and hard fight which he ended up taking to print media to garner attention to this unfair and unwarranted injustice he was facing at the hands of the immigration system (Miller, 1994). Up to 10,000 failed refugee claimants were given another chance after the then Immigration Minister, Sergio Marchi, promised to be more generous to those turned down by Canada's Refugee Board (Miller, 1994). In this second fight, my parents, along with many others, were successful and able to stay in Canada, and my parents finally received their citizenship in 1999. It was their 10 year long precarious status and lack of access to social supports that came along with that, which left them and many other Somali refugees in 
a state of survival. When one is consistently in survival mode, when does integration happen? And how does it affect their children?

My experiences as a Somali artist resonates directly with the purposes of this study. My artwork titled "The Search for Hooyo", examines the relationship between the Somali diaspora community in Toronto and their Motherland. Through a community project, Project Toosoo, I created this photo series to examine the experiences of the daughters of Somali refugees and how their identities have been formed in this middle ground I address as cultural hybridity throughout this study. This photo series has been mainly shared via social media using the hashtag \#SearchForHooyo and shared across Instagram and Twitter platforms while also being on display in art galleries and art shows across the GTA, specifically Borders Inter/rupted, and York's Graduate Student Conference where I spoke about it on an artist panel. As mentioned earlier, my art work expresses cultural hybridity as a form of resilience; my photos have young Somali-Canadian women dressed in the Somali Hido-Iyo-Dhaqan attire, which are dresses meant for the hot desert weather. I place and photograph these young women in typical Torontonian landscapes such as the Toronto skyline, the beach at Scarborough Bluffs, and our many forests and greenspaces across the city. This juxtaposition of "here" vs. "there" showed through the images was intentionally done to facilitate conversations of belonging here in the West. Despite our attempts at living and belonging here in Toronto, our clothing, representative of our identities, does not truly seem to fit.

My participation in the Somali digital diaspora community in Toronto and via Instagram with the hashtag \#SearchForHooyo, has gained traction and allowed me to have the pleasure of interacting with Somalis across the Toronto and internationally who are also examining Somalinimo through the arts. While this is a major positive aspect of the study, where I am 
personally connected to this research and where my work has allowed me to connect with fellow Somali artists, a concern of mine prior to conducting this study was that it would be a great limitation due to the fact that my connections may mainly be with those who have the same viewpoints as me on the Somali identity. This did not end up being the case as will be discussed in Chapter 7.

\section{Chapter 3: Research Questions}

1. Do Somali artists feel that their actions of occupying the intersectional spaces through their art creates a sense of belonging?

2. Are Somali artists in Minneapolis, $\mathrm{MN}$ and Toronto, $\mathrm{ON}$ using social media to challenge, disrupt and create dialogues surrounding the themes of racism, discrimination, islamophobia etc.? If so, how?

\section{Chapter 4: Voices of Literature}

Analyzing belonging and self-identification of diaspora communities in Canada and the U.S. can be directly related to the successful integration of these communities (Berns-McGown, 1999). According to Bhatia and Ram (2001), successful integration is a process in which the host country for new immigrants is receptive of newcomers and their cultures allowing for immigrants to safely practice their home culture while actively participating in the host society. Berns-McGown (1999) describes this phenomenon as "learning to float and even to swim with confidence ... in a sea of unfamiliarity" (p.11), where their home and adopted cultures can be intertwined seamlessly. This is the understanding of integration that will be used throughout this paper. Understanding the processes of integration, particularly of groups forced from their homelands in mass numbers, can be a tricky phenomenon to grasp, and it only gets trickier when trying to understand how this looks for the children of this population. This group 
of second-generation diaspora children/youth who occupy the "third space" as mentioned earlier, of belonging in the middle ground of both/neither here/there, have been finding communities in particular parts of their identities that are shared with others, for a sense of comfort and safety (Gembus, 2016). This is particularly true for the young Somali women, who live at the intersections of Blackness, womanness and Muslimness while at the same time, navigating the world as children of refugees.

\section{4.i. Discourse on Black, Muslim Women and Belonging in the West}

The topic of belonging for Black/African Muslim women has been one that was oftsilenced, overlooked and ignored in academic fields across the West. In Black academia, particularly scholarship focusing on the concept of belonging, the focus has mainly been one that surrounded experiences of Caribbean and African American/Canadians (i.e. those who descended from survivors of the slave trade), with little acknowledgement of continental African experiences as newcomers due to the overemphasis of race being the common factor between all of their experiences (Tettey, et al. 2006). In academic discourse on the Muslim woman and her understanding of belonging it overlooks the Black/African experiences (Mirza, 2013). The absence of the Black/African diasporic Muslim woman from narratives that she should belong in have been detrimental to her sense of belonging and her understanding of where she fits in society. In order to fill these missing pieces, one must explore what currently exists and develop an understanding of what fills the four corners of the metaphorical jigsaw puzzle, before filling in the middle. 


\section{4.i.a. Black/African women and Belonging in Canada/U.S.}

To understand contemporary discourse surrounding the intersectional identity of Black Muslim women, one has no choice but to interact with each identity separately. Very rarely is the Black Muslim woman identity investigated through the lens of belonging. According to McMurray (2007), it is the due to the fact that the Black Muslim woman is not well represented by mass media. Negotiating the identity of Blackness in Canada and the US is to negotiate systems of white supremacy in academia, the workforce and everyday life; a feat that has proven particularly difficult for refugee/immigrant African women, who are unfamiliar with direct experiences with these systems (Tettey, et al. 2006). According to Tettey (et al. 2006), the African diaspora residing in Canada has been attempting to create bonds with this new land they have settled in but have been without success due to the lack of institutional support they received upon arrival. As mentioned by Berns-McGown (1999), integration is a "two-way street" that needs both the state and the newcomer to work together for the process of integration to be successful, but this is not always the case. With what Kumsa (2006) sees as the state's failure to integrate African newcomers, has this population been able to feel that sense of belonging that is so sought after by immigrants? Puplampu (et al. 2006) thinks that belonging has not been achieved. Hybridity, is a term that encompasses the experiences of immigrant bodies and their interactions with belonging in multiple places at once, and this particularly ties in with the African experience in the West, a population that has left their homes for a better life, and have yet to find "home" here (Bhabha, 1994).

\section{4.i.b. Muslim women and Belonging in Canada/USA}

The idea of "home" is an important one for the diaspora population, particularly the diaspora youth who were born in Canada to parents who were born elsewhere. Home is where a 
person knows themselves the best, it is where they can safely live in their identities, not as a physical space but as an emotional and fluid one (Puplampu, et al., 2006). Halls (1992) work also looks at identity as being multiple, intersectional and fluid and yet, belonging and home are distant possessions of diaspora youth. This section on the discourse surrounding Muslims and belonging in academia is missing the voice of those living at the intersection of Blackness/Africanness and amplifies the experiences of South Asian/Arab Muslims. September, 11th, 2001, a date many academics use as a framing point in time for the beginning of the more overt marginalization of Muslims, and visible Muslim women in particular, was a catalyst in the "othering" of Muslim women by mainstream media (Warren, 2018). With this, came intensification of Islamophobia and Islamophobic attacks, which greatly impacted the sense of belonging for Muslim women residing in Canada and the U.S. (Kavakci and Kraeplin, 2017). Evidently, there seemed to be a culture clash between understanding what being a Canadian or American meant, and what it meant to be a Muslim. Mass media outlets facilitated the spread of the narrative that Muslim women needed saving from the oppressive act of wearing the hijab, a material that apparently greatly juxtaposed the image of what it meant to be a Canadian or American woman (Kavakci and Kraeplin, 2017). Where feminism was the crutch holding up these misconceptions surrounding the "plight" of the Muslim woman, the conversation lacked depth, analysis and equality for all women at all intersections (Midden and Pozanesi, 2013). What this created was a sense of unbelonging of Muslim women in the West. Non-Muslim women assumed the role of "savior" whose task was to assimilate the Muslim woman as best as they could, which can still be seen in Quebec's "Niqab ban" recently put in place to prevent Muslim women from wearing their niqab while accessing public services (Bergeron, 2018). The failure to adequately analyze, or acknowledge at the bare minimum, the intersections of 
marginalized identities, according to Patricia Hill Collins (2015), is deeply rooted in the maintenance of racial power structures in the West. An intersectional approach, as mentioned in the introduction of this study, is one that could potentially create room for an adequate analysis to be made of the Muslim woman that would include the Black identity into conversations around the sense of belonging for Muslims in the West. Jiwani's (2018) work examines how conversations in Canadian media regarding the visible Muslim woman plays a role in the negative misrepresentations and therefore the marginalization of this particular population. Jiwani (2018) explains how the media intentionally represents groups in ways that conflates and homogenizes many identities under one static label as a means of solidifying power structures and power relations based on race and identity in the West. The lack of intersectional approaches to academic conversations around identity and belonging is astounding. Often times, authors who claim to have intersectional approaches think intersecting two identities are enough; where the intersectional understanding of Muslim identities created space for discussion on Muslim women, there was only surface level interactions with intersections within the Muslim woman community; Black Muslim women, queer Muslim women, Muslim women living with disabilities, etc., were often silenced and/or ignored narratives. The absence of these narratives in academic discourse indicates an indifference to the experiences of unbelonging for marginalized communities in "diverse" and "multicultural" cities across the West.

Interestingly, some scholars argue that in light of 9/11, the phenomena of surveilling particular identities based on perception shifted; where it was once Black individuals being surveilled for drugs and crime, it was now Muslim's being surveilled for terrorist activities (Finn, 2011). But where does this leave the Black Muslim woman who is now dealing with the effects of simultaneously experiencing Islamophobia and anti-Black racism based on her identity? It 
leaves her on the margins of the margins as can be seen in articles written by Mirza (2013), Swisher (2019), and Moghissi and Ghorashi (2016), all of whom wrote in depth articles about the Muslim experience in the West without mention of the Black experience and the ways in which Black Muslims are doubly targeted by means of Western media outlets influence of public perceptions of the Black and Muslim identities.

Swisher's (2019) piece was interesting given his personal standpoint as a cis-white male whose work delves into the sense of identity and belonging of Muslim women in the United States. His article has a particular focus on Islamophobia within post-secondary education and the ways in which Muslim women feel hatred, discrimination and/or fear play a pivotal role in how Muslim women identify themselves (Swisher, 2019). Gendered Islamophobia, a term coined by Jasmine Zine (2006), is described as the religious discrimination that is experienced by visible Muslim women who are easily identifiable due to their choice to wear hijab, abaya, niqab, etc. It is especially important when understanding that covering is a sign of difference that allows nonMuslims to quickly identify the "other" in a crowd of people (Jiwani, 2018). Swisher's (2019) argument is based on his understanding of the U.S. media's portrayal of the Muslim, usually an Arab Muslim, as someone "backwards", "uncivilized" and in need of saving and this problematic narrative is one that is also spoken about by Moghissi and Ghorashi (2016). Moghissi and Ghorashi's (2016) book Muslim diaspora in the West: Negotiating gender, home and belonging has chapters that speak about identity-based issues of Muslims in Canada, the UK and the United States and brings in many different cultural perspectives that intersect with Muslimness, and yet, the main gap is that it fails to incorporate the Black experience. This is also mirrored in the work of Mirza (2013), who looks at intersectionality and belonging of Muslim women in Britain using interviews with 3 women of Turkish, Pakistani and Indian background. This article although 
strongly aligning with the same issues experienced by Black Muslims such as creating diasporic spaces for personal and community growth in a world of immense marginalization of Muslim women, fails to directly speak to the Black Muslim experience to any degree (Mirza, 2013).

Although academic literature can be found on each particular community, there is a general and homogenizing sweep of the Blackness/Africaness and Muslimness that perpetuates the silencing of those bodies that are already at the margins of these communities. It is at this intersection where Black academics can speak on racism and classism in educational institutions and the workforce without hearing from Black Muslims, who face twice the amount of marginalization due to having "Muslim names" or wearing the headscarf (Davies, 2002). It is at this intersection where South Asian/Arab Muslim bodies can discuss Muslimness in their academic articles without ever creating space for representation from the Nigerian, Sudanese or African American Muslims, and their experiences for their studies on belonging (Mohghissi, 2013) (Swisher, 2019).

\section{4. ii. Role of Media on the Sense of Belonging}

Mass media, as a mechanism of information sharing, has been instrumental in the shaping and framing of discourse around the Black and Muslim identities, having a particularly negative impact on the Black Muslim woman. With a vast majority of Canadian media owned and run by the same few communication corporations, which are predominantly owned by white men, such as CanWest Corporation in Canada, it is unlikely that the general Canadian audience can gain any information from it without it being through the lens of whiteness (Jiwani, 2018). The media plays an integral role in the shaping of representations of the "other", people who, according to Hall (1992), have some type of significant difference from whiteness. 


\section{4.ii.a. Black Women in Mass Media vs. Social Media}

Mass media outlets have developed a particular type of language to discuss Black women in a way that has routinely degraded and exploited one of the most marginalized populations in North America (Richardson-Stovall, 2012). Understanding the historical representation of Black women is crucial in understanding the current depiction of Black women in mass media, the perception of Black women in society, and the reason with which Black/African diaspora women in contemporary times are now shifting their attention to social media to create a more nuanced narrative of themselves. The historical representation of Black women is one that is described by Aime Cesaire (1972) as "thingification"; used to address the effects of the colonial gaze on the Black woman's body that has led to the sexualization and objectification of her body, a prime example being that of Saartjie Baartman, an African woman who was caged and put on display in European zoos and freak shows (Goldman et al, 2014).

Throughout the early 1900's mass medias display of the Black women was done with the use of "Black face", where the casting of a Black person on a television series to play the role of a Black person did not ever take place (Cheers, 2018). It was white folks who would paint their faces Black, accentuate their lips and noses, and wear ripped clothing in order to play the role of a Black person (Cheers, 2018). The stereotypical representations of Black women have been that of the sexualized "Jezebel" and the asexual "mammy" which, according to Hall (1992), are still stereotypes used in today's mass media but has been filtered with more digestible language for the mainstream audience. Chavez's (et al, 1999) work examines the role of race and ethnicity in the formation of discourse on specific identities via mass media outlets and states that due to the media's power to shape and influence the ways in which attitudes and perception against marginalized identities occurs, there have been vast social consequences for many of these communities. The power of exnomination, where the media takes on the role of naming without 
being named, has created room for a specific narrative around Black women that shaped the attitudes of its viewers and has had a significant impact on how Black women are being treated in society (Jiwani, 2018).

McMurray (2007) examines the Black Muslim woman's role in the hip hop culture in the United States and the failure of the hip hop industry to allow Black Muslim women to express themselves as they would like to express themselves. Whether it is Black women represented as the hypersexualized video dancer/rapper, or the silenced Muslim girl who covers all the time, McMurray (2007) described this identity as one that is consistently marginalized through the misrepresentation and lack of representation of the Black Muslim identity in the hip hop music industry. The lack of inclusion of Black women's voices in mass media outlets has left large gaps that have been filled by non-Black women and Black men, who do not have the lived experiences or the language and discourse to correctly or honestly tell the story of Black women. In contemporary times, Black women have found their grounding in mass media, with a few Black women taking up large spaces, including producers such as Shonda Rhymes and Issa Rae who have been producing shows that depict powerful, independent Black women whose characters are esteemed and looked up to by their young Black audiences (Appiah, 2002). Despite this, there is still a major lack in mass media where the Black woman is concerned and so social media has become a key tool in providing counter narratives to these stories. With the rise in social media being a main source of interaction and communication for many young people, this replacement of face-to-face interactions has made it possible for online communities be formed (Mainsah, 2014).

The rise in the accessibility of online social media spaces, and the rise of migration, have led to rapid changes in the term "community" which has developed an alternative meaning that 
shifted away from having any type of geographical border, to large scale manifestations of social interactions based on identity (Everett, 2009). In particular, the Black African diaspora, who have now inherited the Black narrative within North America upon arrival here, have found the means of using Twitter hashtags and Instagram posts in facilitating conversations around the Black experience across national borders. For instance, Sobande's (et, al, 2018), work examines Black women in Britain and their use of social media to resist the marginalization perpetuated through mass media outlets in the UK. In this research, it looks at the digital discourse shaped by Black women's experiences with both sexism and racism and its significance in social media use (Sobande, et al. 2018). Although this study is based in the UK, it bears a resemblance to the experiences of Black women in North American and his work speaks closely to the experiences of the young Black diaspora. Williams (2015) work explores the use of Twitter hashtags that are used to bring attention to issues faced by Black women. The power of social media and Twitter specifically revolves around the power to spread messages quickly to vast audiences, and this article interestingly points out issues through the nuanced lens of Blackness and how hashtag conversations are built around the silence of mass media on these same issues (Williams, 2015). Everetts (2009) piece on digital diaspora speaks to the same interesting intersection of Blackness and woman-ness and how Black women's engagement on social media is particularly sophisticated in how they confront societal issues that they deal with on a daily basis.

One particular example of this is Mainsah's (2014) article discussing young African Norwegian women and the ways in which they engage with their communities on Facebook, Twitter and Tumblr as a means of finding a safe place, away from the racism, classism, sexism, etc., that they face in their daily lives. This article found that young members of the African diaspora had been creating "digital diaspora" communities online due to the internet's ability to 
get rid of the constraints of distance, and these communities were not only sharing music and photos, but also ideologies, iconography, and having discussions on race, identity and belonging in Norway (Mainsah, 2014). This article, plays a major role in the argument of this study; despite being based in Norway, the necessities of belonging for young Africans remains relatively the same regardless of national boundaries. Its use of Halls (1992) work on belonging and identity based on race, and its use of Karim's (2009) work on diasporas use of internet and social media, ties two very important areas of this study together in a well-rounded and thoughtful way that will be used throughout this research.

\section{4.ii.b. Muslim Women in Mass Media vs. Social Media}

From the perspectives of young Muslim women in the West, belonging is a process that involves navigating stereotypes promoted by mass media outlets that are masquerading as the truth. Jiwani's work on Muslim women and "doubling discourses" provides an insightful approach to understanding the ways in which narratives of identity are told through the white gaze, in what she outlines as the power of exnomination which is the power of the media to create discourse or to name a group as "other", while remaining unnamed (Jiwani, 2018). According to Jiwani (2018), Muslim women and particularly visible Muslim women, have been historically mislabeled and misrepresented. Previously, the visible/veiled Muslim woman was extremely sexualized and depicted in language that seemed to exotify her beneath the white gaze (Jiwani, 2018). She was portrayed in mass media as "the sensual belly dancer, the princess, the quarrelsome queen - elusive, a tease and usually a wicked woman" (Jiwani, 2018, p. 489). This narrative has changed in light of $9 / 11$ to continue to mislabel and misrepresent the Muslim woman, but this time as "oppressed", "backwards" and "terrorist", all of which are labels that have been perpetuated through mass media news narratives (Jiwani, p.495, 2018). The 
interesting dynamic here is understanding Jiwani's (2018) analysis of race and gender as indicating factors of the "othering" that Muslim women fall victim to and this research paper agrees with her analysis in stating that mass media plays a large role in the facilitation of "othering". Despite the common understanding of the origination of stereotypes surrounding the Muslim woman and its effects on their sense of belonging, this article fails to introduce narratives that includes an understanding of belonging for Muslims other than those in the South Asian and Arab communities (Jiwani, 2018).

The use of social media in combating these stigmatizations are outlined in Kavakci and Kraepelin's (2017) article on how Muslim women are using fashion to express their identities. One particular instance used in this article of Muslims combating stereotypes of the Muslim woman is that of the "Mipsterz", a term created by and for Muslim Hipsters who wear the hijab and yet do "normal" activities such as skateboarding, hanging out, taking selfies and climbing trees, things that are not usually associated with the Muslim identity (Kavakci, 2017). This type of hybridity of cultures, defined by Kavakci (2017) as a "culture clash", will be explored throughout this research in depth. For many young Muslim women using social media as a means of self-expression, particularly with fashion, the fusion of Muslim/modest attire with Western style has become a token style of "hijabi bloggers" who are creating an alternative narrative to what the mainstream has created of the Muslim woman.

These digital spaces of Muslimness and Western-ness are also explored in depth in Warren's (2018) article which examines "hijabi bloggers" and their social media following that has crossed borders. Notably, this article looks at one blogger in particular, Dina Tokio, who has been using her platform to strengthen the bond globally within the Muslim women community in the face of hate and hostility (Warren, 2018). Warren's work argues that the social media content 
created by these bloggers, i.e. vlogs, blogs, etc., on Twitter and on Instagram have become forms of everyday activism that interferes with the mass media narrative that depicts the Muslim woman as a homogenous group of people (Warren, 2018).

The negative portrayal of Black Muslim women in mainstream media is mainly countered in both the Black/African community and the Muslim community by using social media to reclaim and reshape these narratives to enhance their sense of belonging in the West.

\section{4.iii. Discourse on Somalis in the West}

The contemporary Somali context in the West, can be understood with a brief historical background of the arrival of Somalis and the stereotypes surrounding their identities. As mentioned earlier, the introduction of Somali refugees to the West was not a welcoming one. After the "Somali Affair" where Shidane Arone was beaten to death, and his lifeless body photographed alongside Canadian soldiers, many more Somali's were allowed entry into Canada, possibly a coincidence, but more likely done to rectify the guilty conscious Canada developed over the heinous human rights violation that surfaced with this crime (Fergusson \& Razack, 2004). Oddly enough, the lawyers and prosecutors present at the court proceedings that followed to hold those Canadian soldiers accountable for their abuse and torture of Arone, labelled Somalia as a "lawless land in which well-intentioned peacekeepers were besieged by ungrateful Somalis" and "rough justice" was necessary (Fergusson \& Razack, 2004. p. 89). This misrepresentation of the Somalis in Somalia as lawless and ungrateful was a widespread understanding in the general public of the Somali identity and when Somalis began arriving in the West, it can be argued that it was this public perception that influenced the ways in which Somalis were interacting with the general public and vice versa. 
Unfortunately, there is a noticeable lack of academic literature on Somalis in Canada and the US, most of the studies in this upcoming section are based in the U.K. and although there are similarities, they do not fully capture the experiences lived by Somalis residing in Toronto or Minneapolis.

The concept of internal integration, defined by Berns-McGown (1999) to be the process of "immigrants weaving together their birth and adopted cultures", is a concept that is incompatible with the circumstances under which Somalis' arrived to Canada and the US. With little to no government assistance for integration and settlement of Somalis in Toronto, the process of "cultural weaving" seems to not have occurred as anticipated. Hall addresses issues of identity and how it is developed over time, constantly changing and never stagnant (Hall, 1996), and Somalis, despite entering Canada knowing that their tribe and their Muslim faith was their main identity, were now inheriting the racialized category of Blackness and had to learn to navigate this identity along with the societal struggles that accompanied it. Berns-McGowns (1999) interviews with the Somali communities in Toronto finds that as members of the largest African diaspora, Somalis did not feel they identified with the Black populations of their new homes, such as the Caribbean's and other continental Africans due to their Muslim faith, and as Muslims, Somalis did not find community with the Muslim community which was predominantly Arab/South Asian at the time, due to their Blackness. It was in reaction to the anti-Black and Islamophobic sentiment they experienced both within and outside their communities that pushed Somalis, particularly the younger generation, to find new ways to develop their sense of belonging. This reaction is not uncommon in many marginalized communities. For instance, McMurrays (2007) work in particular examines how young Black Muslim women who in reaction to marginalization and discrimination they face on a daily basis, 
find solace and community in music and the hip hop culture. Su'ad Abdul Khabeer, through the same lens, looks at how young Black Muslims in Chicago, who do not fit into the norm of what a Black person or a Muslim person should look/talk/act like, take this misrepresentation and challenge racism and discriminatory norms through their music (Abdul Khabeer, 2016). In both of these authors works, they are challenging not only what it means to be Black or Muslim in the West in systems of white supremacy, but also what it means to be a Black Muslim within their own Muslim community which is riddled with conscious and subconscious anti-Blackness (McMurray, 2007) (Abdul Khabeer, 2016). Isaac's (1994) work references Robert Frost's line that states that home is "the place where, when you go there, they've got to take you in." and this is indicative of the ways in which Somalis navigated their sense of belonging in this world that was so new and foreign to them (Isaac, 1994, p. 31).

One study based in the UK deals with similar issues of identity and explores the social identity formation of Somalis and the ways in which Somali refugees self-identify when introduced into a new social environment (Scuzzarello, 2013). Scuzzarello (2013) looks at social identity as a way of understanding the subjective experiences of people who share a common history, memories and/or cultural practices. Somalis in this study used this interestingly enough, to socially identify as Muslims first, before attaching themselves with any other identity (Scuzzarello, 2013). Somalis in Toronto in Berns-McGowns (1999) study also chose to identify as Muslims first and as Somali second. This is indicative of the ways in which Somalis adapted to their new homes, they explain in both studies that the Muslim identity was chosen as their main identity because of their interactions with Muslimness in their daily life. From wearing the hijab to sending their children to Quran classes on the weekends, it is their faith, and not race, culture or sex, that kept them grounded in their perception of self (Scuzzarello, 2013). 
The younger generation currently is finding new ways to situate themselves in Western societies who occupy "in-between" spaces (Gembus, 2016). This study, also based in the U.K, examines the role Somali diaspora youth play in challenging negative narratives shared about them by media outlets through artistic expression, including dance, drama performances, visual arts and film making (Gembus, 2016). This collection of Somali youth, created a group called Mustaqbal where they explore their refugee, migrant, Black, Muslim and youth identities through their own lens while also exploring what it means to occupy an in-between space of both traditional and modern cultural experiences and practices (Gembus, 2016). Gembus's (2016) article also mirrors the arguments used in Kabirs (2014) article of young Somalis in UK, Australia and the US and how they navigate their sense of belonging. It argues, similarly Scuzzarello (2013), that collective social identity is key in shaping a sense of belonging, particularly for younger members of diaspora groups. According to Kabirs (2014) study, people can live their lives using multiple identities and navigating between each depending on which suites them at the time; for example, a Somali woman can potentially maneuver Black spaces, Muslim spaces, immigrant spaces, refugee spaces, femme spaces, etc., due to the fluidity of her identity and the intersections within which she resides in.

Belonging for young Somalis, as fluid and nuanced as it is, is a difficult subject to analyze, given that academia has left a rather large gap where knowledge on the young Somali experience should be. The lack of academia available on the young Somali populations residing in Canada and the U.S. is indicative of the marginal social location that Somalis occupy. This study will aim to fill in that gap with a grounded understanding of the young Somali diasporas experiences with identity and belonging and the means through which they explore their identity. 


\section{Chapter 5: Theoretical Framework}

The nuanced approach to identity politics in academic literature and the nature of this study being one that fuses work in both Media Studies and Critical Race studies, makes it difficult for any one theoretical framework to be used in this study. As a study involving the examination of the use of social media to disrupt the experienced negative representations of the Somali Black Muslim woman via main stream media, both Critical Race Theories and Media Studies shape the discourse and literature that will be guiding this research. In order to better situate the research in terms of the lens by which it will be examined through, multiple frameworks will be used. More specifically, this research will be using Representational Intersectionality by Crenshaw (1991) to ground the theories alongside Bhabha's (1994) work on the "Third Space" of cultural hybridity and Halls (1996) discursive analysis of media representation. Each of these pieces play an integral role in understanding how young Somali women use social media as artists to disrupt mainstream narratives and will be explained in relation to this research in the following sections.

\section{5.i. Intersectionality}

Using an intersectional framework allows researchers to develop a multi-dimensional understanding of themes addressed throughout this study such as "postcolonial cultural hybridity", and "digital Diasporas", as a means of combating Orientalist framings of the nuanced identities of Somali women. Intersectionality, coined by Crenshaw (1991), is the understanding that the experiences of individuals cannot ever be explained or shaped by one specific factor (Collins \& Bilge, 2018). Although the term has become so fluid due to its nature of being explored across a wide variety of areas of academia, the complexity of it is one that always ties 
back to power relations and social inequalities based on the intersection in which one is living (Collins and Bilge, 2018). Collins (2015) states that looking at race, class, gender, sexuality, age, nationality, ethnicity, etc., should not be done in isolation of one another, and rather they should be analyzed as relational terms, all of which have effects on the experiences of a person. They emphasize this by explaining how the 1960's and 70's feminist movements with middle class white women at its forefront and the civil rights movements with Black men at their forefront, failed to address their respective struggles through an intersectional approach and therefore, left Black women to fend for themselves in both movements (Collins \& Bilge, 2018). In Crenshaw's (1991) work of examining violence against women of color through intersectionality, she divides intersectionality into three different forms, structural, political and representational, the last of which will be used in this study. Structural Intersectionality is defined by Crenshaw as being the ways race, gender and class oppressions play a role in the experiences of women of color when social or economic reform takes place while neglecting the needs of women of color which has led to a perpetual lack of access to homes, jobs, etc (Crenshaw, 1991, p. 1249). Political Intersectionality is defined to be the parameters within which racism and sexism are defined and countered in political systems by Black men/white women, without racialized women in mind (Crenshaw, 1991, 1251). Representational Intersectionality, although not explicitly defined in the reading, can be understood as the ways in which negative representations of women of color are created through mainstream narratives based on race and gender alongside the understanding of "how contemporary critiques of racist and sexist representations marginalize women of color" (Crenshaw, 1991, p 1283).

In terms of this study, representational intersectionality is the understanding that a Somali woman's experience is not shaped by just her Muslim, African, Somali or Black identity. 
Nor is it shaped by just her age, her gender, her income, nor her sexuality. Rather, a Somali women's experiences are built by all of these and more. In this study intersectionality will be used to address the relationship between the Somali woman and her intersecting identities, which play a large role in the way she navigates social media spaces to build and participate in online communities by creating and sharing identity-based art. More specifically, representational intersectionality will be examined through the respondent's understandings of negative representations of Black, Somali, Muslim women via mainstream media and the further marginalization caused by them.

\section{5. ii. Homi Bhabha Third Space}

The "Third Space" of cultural hybridity as discussed by Homi Bhabha in The Location of Culture (1994) constitutes the understanding that there is a "Third Space" or "in between" space where cultures and identities merge, the fluidity of which is indicated through the way's cultures are practiced by humans who interact with more than one culture. Fanon's work, explored by Bhabha (1994), emphasizes the critical role culture plays in the lives of marginalized individuals, and examines the ways in which connecting with ones "indigenous cultural traditions and retrieving repressed histories" could be understood as a means of practicing agency and resiliency in a society with a dominant culture that differs from their own (Bhabha, 1994, p. 13). Bhabha's (1994) work on culture is interesting in that he examines cultures as identities that are without boundaries, that human interaction is a phenomenon that is always evolving and shifting; there are always new understandings of culture in the ever-globalizing world we are currently residing in. Bhabha (1994) also brings into question an interesting understanding of "Multiculturalism", an "-ism" that is exotified in the Western world and, alongside terms like "cultural diversity", fails to reflect or represent what it actually means to practice foreign cultures 
in the West (Bhabha, p. 50. 1994). Multiculturalism, a policy in place in the Canadian constitution, is one that encourages the peaceful and harmonious coexistence between different cultures and religions in Canada (Legislative Services Branch, 2019). Exemplified in Khan's work, this narrative of being able to thrive in a multicultural society simplifies and erases the complexities that arise when a Muslim woman in particular enters the Third Space (Khan, 1998). According to Khan, Muslim women in the West must learn to navigate the Third Space upon arrival to the West, a task which is often filled with doubt and uncertainty, particularly in terms of identity politics (Khan, 1998). The relationship between this policy, and the "Third Space" is an interesting one for Somali refugees who arrived to Canada while this policy was in place. Despite the constitutional right for a peaceful coexistence, many Somali refugees cite violent discrimination, Islamophobia and racism as reasons for their lack of integration into Canadian society (Berns-McGown, 1999). This research recognizes, through a post-colonial perspective, that the diaspora, many of whom arrived in the West due to civil war and strife, came out of necessity and much of it was not voluntary. In the case of the first-generation refugee immigrants in the Somali community, as is the case for many refugees, their lack of integration meant that their cultural identities remain heavily tied to the homes they were forced from. It is their deep and intricate connection with their home, as will be examined by some of the respondents in the research, that has facilitated in the second generations occupation of the "Third Space", or the "in between space". The space of "in-between" has been inherently occupied by young Somalis who act as interpreters and translators for their parents and practice their home cultures in ways that are either intentional or unintentional, (Mohamud, 2017) all the while residing in Canada as members of this society as fully as they are able to. Through an intersectional lens, this social location of "in-betweenness" can be analyzed and understood to be an indicator of social 
inequality and access to power in itself (Collins, 2012). In this sense, refugees are encouraged to swiftly learn the culture of the host country while solely practicing their home cultures in the confines of their private homes. The children of refugees, the young diaspora, while some struggle to grasp a footing on the culture of their parents, are praised for their ability to integrate into this new Western world they were born into, or brought into from a young age. Bhabha's argument is that this particular space is where individuals can negotiate between the demands of either/any of the cultures and through the use of national/religious texts, technology, language or dress, the individual can transform what was once colonial into something liberating, indicating the resiliency of the person occupying the Third Space (Bhabha, 1996, 38). Being able to occupy this in between space then should be seen as an act of resiliency and agency in a world that confines and marginalizes "the other" to the private sphere through negative representations. As mentioned by Crenshaw (1991), a person's connection to their identities is reflective of their access to power and privilege; meaning that for immigrants in general, their host culture, or the Western culture, is held at a higher regard than that of their home cultures. At the intersection of being a Black Muslim woman, the question persists as to whether they ever fully feel accepted by either community while occupying this middle space.

Using the "Third Space" is ideal for this research due to the post-colonial understanding that comes along with it. Where looking at this through the lens of diaspora hybridity would do the same job of conceptualizing the ways in which young members of the diaspora express their identity, there is a lack of analysis as to why some cultural identities have privilege over others. Bhabha's (1994) “Third Space”, which is grounded in Fanon's postcolonial theory, creates room for dialogue around the relationship between culture and power and the ways in which they manifest themselves in people who chose to practice more than one cultural identity. It allows for 
a more nuanced conversation of identity politics particularly for Black members of the diaspora, who are often forgotten in these analyses.

\section{5.iii. Hall's Discourse on Media Representation}

Hall (1996), states that the discourse created by the West has been used to shape perceptions of individuals or groups of individuals and in its truest form, has facilitated and finalized the development of power relations based on race. Crenshaw (1991) examines what she defines as representational intersectionality, which is the phenomenon of one discourse failing to interact with the importance of the other and this form emphasizes how these intersectionality's are represented in the media. As a hypothetical example of an instance where representational intersectionality is seen, a Somali woman, Hamdi, took her refugee claim denial to the media for support in a case which she believes was due to discrimination. The journalist who wrote the newspaper article speaks to Hamdi's experiences but identifies her as an African woman, provides statistics of refugee status denials of African claimants, and speaks to a representative from an African legal clinic to get their opinion on the African experiences in the immigration system. Although Hamdi is African, when she spoke to the media, she stated that she felt her denial was due to her hijab; it was her religion of Islam that was the main reason for discrimination, but the newspaper article fails to mention this. This hypothetical scenario is not uncommon and through an intersectional framework, the lack of intersectionality shown in this article erases some of Hamdi's experiences and subsequently her identities, leading to an incomplete image and representation of her experience as a Somali with the immigration system. Halls work on discourse emphasizes that the creation of different discourses is not innocent and it is reflective of particular class structures (Hall, 1996). The power relations created by the discourse used by media, "does not represent an encounter between equals" (Hall, p. 88, 1996) 
and alongside Jiwani's understanding of the power of exnomination, the discourse surrounding marginalized identities is worsened by the force of the media whose power is to name and create discourse, without ever being named (Jiwani, 2018). The hypothetical case of Hamdi, raises questions as to what the intentions of the media are when shaping the narrative to erase portions of her identity and how does this impact other Somali women in the long run?

With the underlying understanding of intersectionality, this study will be examining the use of social media as a means of expressing one's identities through the arts. Young Somali women, like many young women, have fled to online spaces when human spaces have become unsafe and incompatible with their practices of the multiple parts of their identities including their culture, religion, gender, race and sexuality, to name a few (Mainsah, 2014). Crichlow's work on Critical Race Theory brings into light the idea and the power of narrative sharing and storytelling for young racialized people as a means of deconstructing systems of subordination (Crichlow, 2015). As examined in the literature review, young Somali women are victims of negative representations via mass media outlets as Black and Muslim, but they also have the power to reconstruct these intersectional narratives by sharing their narratives in whatever capacity they have. Crichlows work provides analytical support to encourage these racialized groups to use their human ability to story tell as a means of reshaping and recreating narratives about themselves (Crichlow, 2015). Social media and subsequently, the formation of digital diasporas, have been the space of sharing that has helped minority groups express themselves, and connect with people who share the same ideologies, thoughts, cultures, religions, etc. (Sobande, et al. 2018). Despite this, as examined through the literature review, the Black community online and the Muslim community online have rarely made space for one another to connect even though there is a large population of individuals who share both identities. It is at 
this interesting intersection that young Somali women, and many other young Black Muslim women, reside and create space for themselves online to share and explore their identities with one another. By using intersectionality as an analytical tool to understand the use of media to share a particular discourse around particular identities, we are able to see the foundation for the societal marginalization of Somali women.

The use of an intersectional lens means moving beyond stereotypical images and narratives of the either living as a Black or a Muslim woman, but rather understanding how she is navigating all of these identities at once. The space the young Somali woman has created for herself online is one of resilience and persistence to feel safe and accepted and will continue to be explored throughout this study.

\section{Chapter 6: Methodology}

\section{6.i. Method: Arts-Based Qualitative Research; In-Depth Interviewing}

Arts-based research is understood to be "research that uses the arts, in the broadest sense, to explore, understand, represent and even challenge human actions and experiences" (SavinBaden \& Wimpenny, 2014, p. 1). According to Bochner (2003), this form of research is best used to understand the "why" behind the art work. In this sense, arts-based research would delve into the way's art can also be a process of healing, teaching, inspiring or provoking thoughts that may otherwise have not been explored (Bochner, 2003). Using art as a form of research allows for the subjectivity of the artist, in some cases the art work speaks on behalf of the artist, and in others, the art is better explained through words (Bochner, 2003). Given that historically, art has played a large role in being a form of expression to address socio political concerns, the fusion of arts and research in arts-based research could allow for a deeper connection to the thoughts and ideologies behind different societal issues that are examined through research (Knowles \& Cole, 
2008). Phenomenological research is a research where respondents are chosen and interviewed based on their experiences of facing the same or similar situations and understanding the ways in which they reacted or responded to those situations (Neuman, 2011). This type of phenomenological qualitative inquiry was used in the hopes of gaining a clear and well-rounded insider perspective on the lived experiences of Somali artists and the ways in which they use their art to interact with themselves and the world around them. This is an examination of their sense of belonging and the ways in which they counter negative representations about their identities and this is done through the lens of art to provide more in-depth narrative-based research. By interviewing digital artists, singers, photographers, and poets, this research aimed to look at the artistic creations of Somali women and how it reflected their identities, their understanding of themselves and their sense of belonging while challenging mainstream narratives about their identities. This research would not only add to the vast amount of literature available on diaspora populations in the West, but it would also fill an academic void where phenomena pertaining to the intersection of being a Black Muslim woman of the diaspora is rarely addressed. The Somali voice is one that is often silenced or overlooked in academic literature surrounding Black bodies and Muslim bodies and as this research finds, it is not restricted to academia; there is a disregard of the Somali woman's voice in particular, even in the arts communities.

As a member of the community being researched, there are a few underlying assumptions and ideas that I brought into this research initially. The main assumption was that young diaspora artists are creating art in order to better situate their identity in regards to the power of "Whiteness" in Western society. As a victim of Islamophobia and anti-Blackness at the hands of White individuals, I retreated into the arts as a safe haven and retreated into my community for 
healing. I assumed that this is could be the reaction of all racialized artists but as will be examined in the findings and analysis portion of this essay that is not necessarily the case. Although anti-Blackness and Islamophobia are explored, in many cases, the perpetrators are members of their own community which adds a layer of marginalization to the Black Muslim female identity.

This research is not representative of all members of the Black Muslim and Somali communities. Rather, as Dorothy Smith (1987, p. 157) argues, this analysis of the Black Muslim experience could and should be a point of entry into the examination of larger social processes and issues faced by these communities. My standpoint is one that is involved with the community being researched, but is also one that has set boundaries by participating in reflective journaling to ensure the responses are not being misinterpreted through bias. Although bias sometimes plays a role in the compilation of research, this research in particular seeks to both identify as well as speak to this topic beyond my personal bias while challenging my own personal assumptions.

In order to correctly analyze and synthesize the intentions behind the bodies of work created by this young population, following ethics approval from Ryerson's Research Ethics Board, social media outreach began on Instagram. As a Somali woman and artist, the researchers personal standpoint was used to her advantage to not only secure participants for this research but to also develop a more intimate level of trust that can truly be understood and analyzed sincerely by a member of the community. Although it is a strength in this sense, it is also a weakness in that, despite the confidentiality agreement, participants may have felt the need to omit responses that they felt were too personal to share in this research. The Recruitment Ad (See Appendix A) was used to gauge interest from prospective participants. The researcher being 
well connected to the Somali arts community, surprisingly was of little assistance to this research, only 3 out of the 6 participants were personally acquainted to the researcher. Finding participants from Toronto was simpler than finding Minneapolis participants, as most of the researcher's social media followers were Toronto-based. It was with the help of re-shares from mutual followers and personally reaching out to Minneapolis-based participants that they were secured for the research.

Semi-structured in-depth interviews were chosen as the best method for this research in order for there to be room for the respondents to answer as best as they could without the worry of limitations for their answers. It also created a space for the interviewees and the researcher to interact as equals. This method was also used as it seemed to be the best way to facilitate trust and respect throughout the interview process to ensure that the most honest responses were provided. This work relied heavily on the honest and balanced personal narratives and experiences of the respondents (McMillan \& Wergin, 2002).

\section{6.ii. Sample - Participants}

Table 1.

\begin{tabular}{|l|l|l|l|}
\hline Name & Age Range & Type of Artist & City of Residence \\
\hline Sumia & $18-22$ & Singer & Toronto \\
\hline Nastexo (pseudonym) & $18-22$ & Digital Artist & Toronto \\
\hline Wasima & $18-22$ & Digital Mixed Media Artist & Minneapolis \\
\hline Naeema & $23-25$ & Motivational/Spoken Word Artist & Toronto \\
\hline Sabrena & $18-22$ & Photographer & Minneapolis \\
\hline Ifrah Mansour & $30-35$ & Multimedia Artist & Minneapolis \\
\hline
\end{tabular}


The participants of this study come from two cities with the highest population of Somalis in North America; Toronto and Minneapolis. This study aimed to gather responses from Somali artists from the ages of 18-35 as this would be the age of Somali artists who were either born in the West or came here as refugees at a very young age. The purpose of this age range was to ensure to not only give a voice to artists who are established in the Somali community but also to the younger ones who have a heavier online presence, are in the early stages of their artistic journey and have yet to fully delve into the influence they can have with their art.

These artists were mainly recruited through Instagram and word of mouth, and as the researcher does not use Twitter, members of the community also shared the Recruitment Ad on that social media outlet. Recruitment was conducted via social media with the intention of grasping the attention of Somali artists and users of social media who have been sharing their work with their respective audiences. All of the Toronto respondents were recruited through the sharing of the Recruitment Ad on Instagram. As for the Minneapolis respondents, Sabrena was recruited from word of mouth via Twitter and the researcher reached out personally to both Ifrah and Wasima via Instagram and email after being referred to them by a Toronto-based artist who was not a participant in this study. Once the participants got in contact with the researcher, the consent form along with a more in-depth explanation of the study was sent in response for the participant to examine and ask questions in regards to the consent form. Securing, scheduling and conducting the interviews for the 6 participants took around 3 weeks from June 10th-July 5 th of 2019, all of which were conducted via video or audio calling, depending on what was accessible or comfortable, and lasted between thirty minutes to an hour. Confidentiality was maintained between participants by ensuring reference was not made to responses by other respondents nor was any reference made by naming other participants. 


\section{6.iii. Procedure: Data Collection and Analysis}

Through an inductive data analysis, the researcher interviewed the respondents prior to arriving at any conclusions or analyzing themes for this study (McMillan \& Wergin, 2002). This ensures that the conclusions were drawn from the bottom up rather than from the top down which eliminates room for biases and misinterpretations (McMillan \& Wergin, 2002).

Semi-structured interviews were chosen as a means of collecting data to allow for a more conversational manner of interviewing that would leave the respondents open to explore their own artwork and the ways in which it interacted with their sense of belonging in the West (Longhurst, 2016). A list of predetermined questions were written out and approved but the semi-structured interview set-up created space for the interviewer and interviewee to explore a wide variety of topics while staying on track (Longhurst, 2016). For instance, all of the questions used in the interview (See Appendix B), were asked, but due to the flow of many of the conversations, with the exception of two, this question was asked as a follow up question, "Does your art help you feel like you belong?". The reason for this follow up was due to the conversations from their previous responses regarding the impact mass media narratives had on their artwork and due to many responses explaining their attempts to bring their own voice to the forefront in regards to their own stories, it felt like a logical question to ask that would add to the depth of the research.

All 6 of the interviews were audio-recorded and transcribed to later be analyzed. Patterns and themes were then identified and interpreted through a thematic analysis of the responses (Guest et al, 2012). In conducting a thematic analysis, both implicit and explicit ideas shared throughout the interview process were used gathered, and due to misinterpretations, that can arise from the implicit ideas, all interpretations were double checked by respondents throughout the writing process (Guest, et al, 2012). 


\section{6.iv. Strengths and Limitations}

The strengths of this research lay in the opportunity to broaden the literature available regarding young Black Muslim woman, a population that has often been silenced and overlooked both in academic literature, and as this research finds, in mainstream media narratives (McMurray, 2007). It identifies the nuanced identities of young Somali women in particular, all of whom play a role in using their voices to explore their identities and teach their audiences about themselves while challenging mainstream narratives. The researcher places an emphasis throughout this research on the idea that Somali women are not a voiceless population, rather they are a silenced population who have been provided limited to no space to share their narratives within mainstream media outlets but have been using social media to amplify and express themselves through any means available to them.

This research also provides a better understanding of what the concept of belonging looks like for the Black Muslim diaspora population in both Canada and the United States. It particularly looks at the ways in which they artistically express themselves and their sense of belonging. It also focuses on how each of the artists feels about the ways they are represented in the media and how they are reshaping that with their work. The effects of the misrepresentation of the Black Muslim woman in mainstream media is not often examined through academic literature and this piece of research could be the start of a more intricate set of knowledge regarding the social consequences of negative media portrayals of marginalized populations. Many of the respondents also addressed their sense of belonging within their Black communities and Muslim communities and this intersection was one that is often silenced within both communities.

The limitations of this study include the small sample size of 6 individuals which may not depict the actual experiences of all Black Muslims nor all Somalis, a point which I would like to 
emphasize. There is also the personal bias of the researcher who is an artist whose work examines concepts of belonging for young Somalis in Toronto and Minneapolis. Due to my own interpretations of my artwork, it leaves room for possibly misinterpreting responses but this is avoided through reflective journaling which was completed after every interview to remove personal biases from this study. Another limitation of this study was that due to the depth of the interviews, many topics were addressed, all of which could not fit into the scope of this study. This means that there is ample room for future academics and researchers to expand on topics regarding the Black Muslim identity.

\section{Chapter 7: Findings and Analysis}

The conceptualization of responses provided by participants involved analyzing the responses and developing common themes that correlated with this research. The purpose of categorizing the responses under the chosen themes was to ensure that not only were the research questions answered, but to attempt to start filling in the gaps in the literature that were found throughout the literature review. Spaces of (un)belonging was chosen as a theme due to each respondent's emphasis on their artwork being a reaction of, or a means to, feel a sense of either belonging or (un)belonging in the Black, Muslim, Somali, American or Canadian communities/societies. Lack of representation and the misrepresentation of the Black Muslim Somali woman was chosen as another theme due to the consistencies in each participant's responses to divulge their feelings regarding the negative portrayals of their identities in the mainstream media. Agency in storytelling is a theme that was chosen to provide space in this research to delve into the ways in which each of these artists have taken up space to share their narrative in an honest and wholesome lens for the sake of healing and self-care. Challenging and 
disrupting mainstream narratives was chosen as a theme due to a common attempt by each of the artists to create art that was different from what mainstream narratives shared. Lastly, the "Third Space", or the "in between space" was chosen as a final theme to explore for the sole purpose of bringing forth the resiliency that is practiced by some of the Somali artists to incorporate their Somali and Western cultural identities into their art work.

\section{7.i. Spaces of (Un)Belonging}

To belong, in the constructivist sense, is to understand that your ability to feel like a member of a certain group, community or identity is never fixed, final or binding (Kumsah, 2006). It is a sense that is in constant movement depending on one's understanding of their social location and can sometimes be altered by one's sense of acceptance within that particular group or identity (Kumsah, 2006). According to Kabir, identities that individuals choose to ascribe to can be attributed to their "place of birth, ancestry, place of residence, length of residence, upbringing and education, name, accent, physical appearance, dress and commitment to place”, all of which are known as the "ten identity markers" (Kabir, 2014). As will be seen throughout this section, the ways in which participants have chosen to identify have always gone back to one of Kabirs (2014) ten "identity markers" mentioned above.

At the beginning of each interview, one of the first questions asked was, "What community, group or identity do you feel like you belong to?”. This question was met with mostly the same responses; the Somali identity was one that was mentioned by all participants. While the three respondents from Toronto; Sumia, Nastexo and Naeema commonly ascribed themselves as Black, Muslim and Somali, the three respondents from Minneapolis chose to ascribe themselves differently. Interestingly, Wasima identified mainly with her Somali-Muslim- 
American identity, Sabrena identified with her Somali and Muslim identity and Ifrah identified with the Somali, Muslim, Black, Refugee and "New American" community.

This slight difference of self-identification is one that, after a few interviews took place, stood out to the researcher. What is occurring when young Somali-American women leave out or mention last, their Black identities? Referring back to intersectionality, the experiences of Somali women in the West is not homogenous, rather it is made up of multiple factors that include the social-political climate in each nation and local community (Crenshaw, 1991). According to Hodan A. Mohamed (2017), the Blackness of Somalis is always questioned, and her work interacts with Rinaldo Walcott's work who also explores the erasure of non-Caribbean Black people in Canada despite the heterogeneity of the Black diaspora (Walcott, 2018). The same could be said regarding the Black identity in the United States. According to Sabrena, one of the respondents who did not mention Black as one of the groups she belonged to, she addressed how she felt like she could not identify as Black due to her African-American peers explicitly telling her that she was not Black because she did not share the history of enslavement. This claim is not an uncommon one as many African Americans ascribe Blackness to being a descendant of the Trans-Atlantic Slave trade, which, in essence, is an erasure of the Somali's experience in the Arab slave trade system (Mohamed, 2017). Ifrah, who did mention Black as one of her identities, addresses the Somali relationship to Blackness in the United States by stating;

I came to America when I was 10 ... I bought into the identity I was given which is, the African-American. I remember sitting at a lunch table with another African-American girl and she was new to the high school and she asked me because she had never seen a Black Muslim before. She asked, "What are you?" and I said "I'm African-American" and of course she's seen me talking to other Somalis in Somali so she said "No you're not" and I go "What do you mean? I'm an African-American just like you." and she goes "No, I don't speak what you're speaking so you're not African-American. African-Americans don't speak Somali" and she was saying things like "You're Black and from Africa and I'm Black from America." It's really interesting how that moment had just stayed with me (...) how damaging these ascribed identities can be and it's so easy to erase peoples' histories and 
cultural identities. Here in America, we're lazy and like to put everyone in 3 boxes and say "Pick one!" - Ifrah, Minneapolis

Ifrah's interaction with Blackness brought up complex identity notions from a young age that excluded her from an identity she was socially ascribed to. It was interesting to note her particular navigation of this situation that occurs more often than not in both the US and in Canada. Mohamed (2017) also notes that the multiple identities of the Somali woman can sometimes mean that she may not always feel accepted in non-Muslim Black spaces; the fact that some Somali women are visible Muslims, meaning hijab-wearing, is sometimes an automatic exclusion from the Black community. McMurray (2007) notes a similar understanding of this sense of belonging, particularly in the United States where, as will be examined later, representations of what a Black woman is or what a Muslim woman is, make it so that Black Muslim women are often excluded from spaces where they are meant to belong, i.e. non-Black (Arab/South Asian) Muslim spaces and non-Muslim Black spaces.

The concept of belonging came up quite often throughout the interview, and for that reason, I diverged from the interview questions slightly. Rather than only gathering responses regarding which communities each participant belongs to, I inquired further by following up with a question on whether or not each artist's work helped them feel like they belonged. Both Sabrena and Ifrah felt that the work they created through photography and multimedia work respectively, helped them feel like they belong. Sabrena attached her sense of belonging to her ability to make a difference in her community with her art. Ifrah's sense of belonging was grounded in her ability to create a safe space with her art to heal from past traumas, particularly within the Somali community. Wasima, similar to Sabrena, indicated that her sense of belonging was attached to community and being able to network and connect with other artists and build relationships online and offline. This phenomenon, explored by Mainsah (2014), is defined as 
belonging to the "digital Diasporas" where young people, specifically young African members of the diaspora, have found means of connecting with each other and imagining a sense of belonging through online relationships and communities.

Interestingly, Naeema responded that her art did not help her feel like she belongs to the non-Black Muslim community nor the non-Muslim Black community, rather she felt the most sense of belonging in the Black Muslim community. White supremacy and the associated dominance of whiteness, are inextricably linked to the normalization of anti-Blackness and Islamophobia, and this has a particular impact within racialized communities. This means that the common ground and empathy that should exist amongst racialized and marginalized communities, does not exist (McMurray, 2007). Rather, it is common for Islamophobia to take place in the non-Muslim Black community, and for anti-Blackness to exist in the non-Black Muslim community (McMurray, 2007). Due to this phenomenon, it is at the intersection of being a Black Muslim where Naeema felt she was neither a victim of Islamophobia nor anti-Black racism and she could safely share her work without filtering herself in an attempt to make her audience comfortable.

Modesty within the Muslim women community is an often debated and spoken about topic particularly on social media (Kavakci \& Kraeplin, 2016). Social media has created the space for young Muslims to create conversations around modesty and how it could look differently for every individual. Sumia briefly discusses modesty in her interview when it comes to her artistic creations. As a singer, she describes her constant presence in male-dominated spaces and the expectations laid on her to conform to the industry's beauty standards in order to sell her music. Although she does not wear the hijab, Sumia's comfort and sense of belonging in spaces like the studio, where her art is created, is challenged when she is unable to maintain her 
modesty both in reference to her physical appearance and in terms of her lyrics. Sumia addresses this by stating;

"And I guess it's 'cause men have an upper hand in this industry (...) I'm not trying to make love songs or like sexual songs and they're always trying to mold me into it. I don't even think they're consciously doing it but they're always trying to persuade me to write a certain way or sing a certain way that I can never do (...) I feel like this all comes around to this idea that Somali are women are just this object of being just being pretty and looking pretty. And they think this is how they'll get views or sell in this industry, just by the way they look." - Sumia, Toronto

As mentioned by Jiwani, the hijab is a physical identifier and reminder of difference (Jiwani, 2018). Despite the large population of Black Muslims in the West, reconciling the Black and Muslim identities seems to be one of great difficulty for many. McMurray (2007) and Jiwani (2018) both reference the mass media image of the typical Muslim woman, who is usually fully covered and Middle Eastern and McMurrays (2007) work emphasizes the particular lack of representation of the Black Muslim woman in these images. With this imagery created, and as addressed by some of the respondents, it is especially difficult for a Muslim woman to be imagined without being fully covered, and similarly difficult for a Black woman to be imagined without being hypersexualized (McMurray, 2007).

\section{7.ii. Lack of Representation and Misrepresentation}

Jiwani's work succinctly summarized the experiences of being a Muslim woman as one that has been historically misrepresented in mainstream media and her work interacts with Edward Said's idea of the conflation of representations of Arabs, Islam and Muslims (Jiwani, 2018) (Said, 1991). But if representations of Arabs and Muslims are conflated, where images of Brown and Arab women are often used in the forefront of these representations, what are the effects on Muslims living at the intersection of Blackness? 
According to McMurray (2007), the mere existence of the Black Muslim woman is a challenge to the mainstream representation of who the Muslim woman is. This is not something that occurs just at the intersection of Muslimness, but also at the intersection of Blackness; the Black Muslim woman's existence challenges the representation of who the Black woman is. In either case, this woman who is residing in the periphery of two marginalized identities, is open to further marginalization due to her intersectional identity.

It is not uncommon for Americans to learn about who Muslims are from mainstream media outlets and according to Swisher (2019) as of 2017, it was reported that a mere $45 \%$ of Americans actually knew a Muslim personally. During the interviews, in response to being asked about what they see on mainstream media regarding identities and communities they belonged to, all respondents mentioned negative portrayals with the juxtaposition of a few Black Muslim women who have "paved the way" as Naeema put it. Sumia felt that women she identified with were hypersexualized in media and music in particular, citing the U.K. grime and underground Toronto rap genre as the main culprits of the fetishization of the Somali woman and her body. On the other hand, Nastexo and Naeema similarly stated images of oppression and victimhood and a silenced identity under the imagined "patriarchal structure of Islam" as the main negative representation of their Muslim identities, a representation which Sabrena states, in the context of the United States, led to "a cloak of hatred covering the whole country". McMurrarys (2007) work similarly addresses this dichotomy of representations of the Black woman and of the Muslim woman that is spread through mainstream media outlets and created by systems of Muslim, White and Black masculinities, under which the Black Muslim woman essentially falls victim to. She writes that the stereotypical "good girl" role of the Muslim girl who is veiled and submissive, in contrast to the Black woman who has been historically hypersexualized under the 
white gaze and the gaze of the media, make it difficult for a Black Muslim woman to exist and be neither of these things which has restricted them from participating in unconventional career, such as working in the music industry and as this study shows, working in the field of digital media and exploring artistic representations (McMurray, 2007). When a Black Muslim woman exists, she is defying these representations that actually further marginalize and invisibilize the Black Muslim woman and her lived experiences (McMurray, 2007).

\section{7.iii. Agency in Storytelling}

Crichlows work in storytelling indicates that there is power in having the capacity and agency to share one's personal experience among a group of individuals who may or may not share common experiences as a means of self-reflection and healing and a learning opportunity within the classroom space (Crichlow, 2015). His work relies on the assumption that the power lies in being able to disrupt the dominant educational curriculums by listening to the lived experiences of individuals whose stories are generally erased or silenced, for example the indigenous experience in Canadian classrooms (Crichlow, 2015). With this approach in mind the effects storytelling could have via social media can have a much larger impact both in the potential healing process for the individual who is sharing their story and as an educational tool for the audience.

During the interviews, I gathered as much information as I could regarding the forms of art each participant explored as well as their intentions behind their art work. The power of social media is that it allows the work and voices of its users to be amplified. Young Somali artists have built their audiences based on the narrative sharing and being able to connect with not only 
other Somalis, but also Black Muslims in general as well as non-Black Muslims and non-Muslim Black women. Ifrah felt her work was a power in itself and states;

"I do feel like it's a power in the palms of your hands...I chose to tell my story as I lived it and my story just happened to be shared by a whopping 90,000 Somalis here in Minnesota." - Ifrah, Minneapolis

Her response to the question indicated that she felt her art brought community together and showcased the Somali identity in ways she felt the story should be told. There is power in being able to tell your own story in a positive light, rather than have it told by someone outside of the community who does not share the lived experiences of that community. Nastexo practices the power she has in her graphic design art creation process by intentionally ensuring that all the characters in her work are Black/brown bodies, to allow for representation of these identities that are rarely showcased. This feeling is echoed by Sabrena who believes that representing Muslims positively via social media could potentially have a strong impact on how others view Muslims and how Muslims view themselves. Naeema mentions how accessible social media has become for young Black Muslims to be able to tell and "find out the truth for themselves", indicating a parallel between Crichlows (2015) understanding of storytelling in the classroom and storytelling online. Naeema further explains;

"It has allowed us to sort of speak for ourselves and create our own counter perspective of what Islam and being a Black female is" - Naeema, Toronto

Wasima and Nastexo similarly describe the fact that social media has now "levelled the playing field" for young Black Muslims to be able to tell their own stories and make room for themselves to share these stories.

“... art is a tool we use for our own positive narratives... And you're voicing your story through your lens and nobody else can do so for us. I think that's very powerful because we don't have to wait for anyone to do it for us, we're doing it for ourselves now." Wasima, Minneapolis 
In this passage, Wasima ties sharing personal narratives with the ability to feel empowered. Social media has provided the means for young Black and/or Muslim people to leverage and amplify their voices through the creative arts and in doing so, have built audiences who are now learning from their experiences. The media's power of "exnomination," coined by Jiwani is known as the power of the media to create discourse without ever being named themselves, and it is now being dismantled by the ways in which young Black Muslims are making use of social media (Jiwani, 2018). The power of mass/mainstream media to be the voice and share the narratives of marginalized members of the community is now being challenged by users of social media, particularly artists who are sharing stories through the arts and reaching large numbers of audiences. In other words, there is no longer a need for Black Muslim women to rely on mass media outlets for accurate representations of themselves. Although the power of mass media to construct stories/narratives of marginalized people still exists, social media now allows for alternative narratives and stories to be shared that challenges mainstream narratives.

\section{7.iv. Challenging and Disrupting the Mainstream}

Challenging mainstream narratives is not an easy feat, but as many of the artists brought up, it is something that is done inevitably when all of the narratives shared by mainstream media are misrepresentations and false narratives. When asked whether they felt their art was a means of disrupting or challenging the mainstream media narratives, the responses were the same. While all of them understood that their work was disrupting mainstream media narratives, there was a difference in whether their work was doing so intentionally or not. 
Sumia as a singer, has intentionally been changing the hyper sexualization of Black and Somali women in the music industry. Through both her lyrics and dress/style, she has been straying from the norm and sharing her lived realities in the best way she knows how. She points out a few lines of her lyrics including "Somali queen from the west end" and says "I like when I say it because it doesn't sound fetishizing when I say it". She also challenges ideas of "professionalism" by sharing with me that she intentionally leaves her hair curly when meeting with producers or when performing in an attempt to defy the typical beauty standards placed on many Black artists. Richardson-Stovall's (2012) work outlines how the archetype of the Black woman portrayed by mass media has often been one of exploitative and degrading nature and it is in defiance of this exploitation that Sumia attempts to reconcile her energies as a Black Muslim female singer and use her voice and lyrics to uplift young women who share her identities. Naeema, through her motivational poetry also felt her work "actively counters" narratives that are shared specifically about the Muslim woman, but describes it as an "emotionally draining" process. Sabrena stated that mainstream media played a role in her artwork but only unintentionally as she was intentionally trying to avoid being influenced by mainstream media in her art. She felt if she was influenced by mainstream media and intentionally countering mainstream narratives, it would not be work she would enjoy and states;

"I wouldn't be able to do things for myself that I personally liked and felt proud of. I'd be doing it more for other people to look at that and say "that's amazing" and I'd probably hate it, you know?" - Sabrena, Minneapolis

Sabrena felt that any over-influence of mainstream media narrative in her work would take away from what she enjoyed doing and similar to Naeema, this can be related back to the emotional labor that is required to tell these stories through the arts. Ifrah on the other hand explains that the hyper-sensationalization of Somali trauma in mainstream media is something 
that she challenges but she feels she does not do this on her own. Rather she feels like it is a communal effort to disrupt these narratives being shared and she shared the following story during her interview;

"I saw this Somali elderly that opened the news box (...) there were some horrible stories that were about Somalis on the front page and this grandma opened the box and took the first one. She just flipped it and walked away. I was waiting for the bus and it was just really interesting because who on Earth wants to see some horrible things that are attached to your identity constantly and exposing that your children, of course the elder knew that it was a bus stop, a lot of kids - Somali kids - take the bus." - Ifrah, Minneapolis

In this instance, Ifrah was a witness to someone intentionally disrupting mainstream narratives in a way that may not have had a grand impact on society, but even flipping a newspaper upside down so that young people are not seeing false representations of themselves is enough to create even a little bit of change. Media representations of marginalized people are done intentionally; the ways in which discourse is used to define a situation can implicitly and/or explicitly create a hierarchy that privileges some groups over others based on the ways in which the group is represented (Jiwani, 2018). That being said, the ways in which Black, Muslim and Somali identities are represented have left those living at this intersection in the periphery. Some Somali artists have taken it upon themselves to intentionally and unintentionally challenge or disrupt this narrative, and it can be assumed from some of the responses that this task is not just taken up by Somali artists but also by the wider community in general as a means of reshaping the narrative to be a more positive one.

\section{7.v. Third Space and Resiliency}

The Third Space, introduced by Homi Bhabha (1994), is the "in-between" space of fluidity of identities and cultures occupied by individuals who practice or interact with more than 
one culture. The Somali diaspora in the West, having only first started arriving in waves in the late 80's and early 90's as a result of war and political instability, were thrust into this world without having many established members of the community to assist in the settlement process (Berns-McGown, 1999). This meant that the refugees had a very difficult time integrating into a Canadian and American society and that it was their children, or the refugees who came at a very young age, who most experienced the phenomena of existing in the in-between space of having their daily lives and interactions being influenced by both Somali and Western culture.

This research placed an emphasis on the experiences of Somali artists and the ways in which their art interacts with both their Somali identities and their Canadian or American identities. One of the questions asked to each participant was how their art is influenced or interacts with each of the identities. Sumia shared that she felt that her music being influenced by her Somali culture was inevitable because of the fact that Toronto's rap/RnB scene is occupied by many Somalis.

"I think Somali culture is the urban culture in Toronto (...) half the slang words in Toronto are Somali words like kawaal, warya, walahi (...) So when you say how do you fuse Canadian and Somali, I kinda don't know how to (...) Ifeel like we already made it into one." - Sumia, Toronto

Nastexo intentionally tries to fuse her identities through her art by using the color palette of the Somali alindi, a fusion of different shades of yellow, red and orange. She also says her work is influenced by the textures of the Somali fadhi carbeed ${ }^{3}$ but she recognizes that this may not be intentional, rather they are colors and designs she grew up with and so, they have inadvertently influenced her art. The content itself, which consists of Black/Brown women

\footnotetext{
${ }^{3}$ Fadhi Carbeed is the term used to describe seats in the Somali house hold that are made up of flat cushions and are low to the ground. Usually used in living rooms instead of Western style couches.
} 
designed with swirls and patterns of different shades of brown usually sitting or standing in ways that make them look royal, is considered by Nastexo to be Westernized content.

Naeema considered her poetry to be a place where her identities can safely converge and added that besides through her art, and as explained in the earlier section, Spaces of (Un)belonging, it is difficult for Naeema to find space where all of her identities can safely exist. She states that she takes "ownership" of her craft and fuses her Black, Somali, Muslim, Western and gender identity to properly address all of her intersections in her art. Puplampu's (2006) work examines "diasporic activities" and how hybridity of cultural identities plays out for African women in Canada. This work paired with Mainsah (2014) examines the predicament of young members of the African diaspora to learn from and share with each other by connecting on their shared experiences of hybridization (Puplampu, 2006) (Mainsah, 2014). Naeemas work of spoken word poetry exemplifies this attempt to connect with other members of the community who share her experiences in the hopes of creating that safe space of healing.

Wasima, similar to Nastexo, uses the Alindi pattern in her art work, and specifically spoke of her piece on Iman Warsame, a Somali supermodel who graced the runways for most of the 80 's and 90 's, that portrayed "both the past and the future of Somali women.". Wasima's work also intentionally inputs her Muslim identity into her graphic designs by ensuring that she includes women in a hijab so that her work can connect with hijabi women and non hijabi women alike. Sabrena's artistic journey began with a list of things that she sought comfort and happiness in and stated that her mother's Somali cultural clothing was the first thing on her list. Her work has surrounded young Somali American women wearing Somali clothing and incorporating both identities in the work. 
Meanwhile, Ifrah, a multimedia artist has taken part in bringing the Somali identity to the big screen in a film called A Stray, has put on plays, and is an art teacher. Her work intentionally incorporates the Somali culture and often speaks to Somali elders in her community who teach her about the Somali life prior to the civil war in order to share these experiences with the younger generation.

"I'm constantly just wanting to collect these stories and I have these memories so I can pass down to America-born Somalis and I feel that's so important because we are people who passed down knowledge, history and culture (...) and we need to find ways to continue to do that" - Ifrah, Minneapolis

Puplampu (2006), whose work explores understandings of home, explains the process of migration and the disruption it causes to a sense of identity. When one leaves from the physical construct of what they believed was their home, they begin to rely on their mental connections with that home (Puplampu, 2006). All of the participants work relied heavily on the mental connection with the home their parents spoke of, incorporating clothing, household decorations and oral stories that are connected with their Somalinimo into their artwork. This is not uncommon for diaspora communities in general, who use the arts to connect with a home some have never physically travelled to. In essence, the arts, here, are used as a means of building and maintaining that connection with their parents' cultural identity and when the young diaspora use it, it becomes a culturally hybridized version that occupies a space between their Western self and Somali self (Puplampu, 2006).

\section{Chapter 8: Discussion and Conclusion}

The goal of this study was to develop a more in-depth understanding of the ways in which young Somali women use the arts to occupy intersectional spaces while using social 
media to disrupt and challenge the narratives shared by mainstream media outlets. The research questions are as follows;

\section{Do Somali artists feel their actions of occupying intersectional spaces through their art creates a sense of belonging?}

2. Are Somali artists in Minneapolis, $M N$ and Toronto, $O N$ using social media to challenge, disrupt and create dialogues surrounding the themes of racism, discrimination, islamophobia etc? If so, how?

Using an intersectional framework to contextualize the responses provided by each participant allows for a more multi-dimensional understanding of the response and the researcher was able to move away from analyzing these experiences just through the lens of the Black, Muslim or Somali identity, but rather examine the individual experiences through the lens of all of these identities at the same time (Crenchaw, 1991). It created a space for analytical discourse to be created about the nuanced experiences of Somali women in particular and how their art interacts with all of these identities at once in an attempt to both heal themselves and disrupt the negative mainstream narratives surrounding each of their identities.

Through a phenomenological approach, this research found that the experiences of Somali artists who share their work via social media could be broken down into themes that fully encompassed their intentions and the outcomes of attempts at belonging into society and challenging mainstream narratives. Where young Somali artists may not have partaken in selfinquiry regarding their work, the questions asked during the interview process created space for each artist to delve deeper into the art they have created from an intersectional lens and understand in what ways it interacts with each identity.

The findings of this research agree with much of the work cited in the literature review, including Mainsah's (2014) work on African diaspora women in Norway which argues that the online interaction created through sharing ideologies, thoughts and art online have played a large 
role in the perception of self and the connection to their country of origin, for many (Mainsah, 2014). The notion that Muslim women use social media to counter false and negative representations of themselves explored through Kavacki and Kraepelin's (2017) work has also been proven to be correct for the respondents in this study. Lastly, McMurray's (2007) work on the marginalization through misrepresentation of the Black Muslim women has been a common topic of discussion throughout the interviews and each artist, in her own way whether intentionally or unintentionally, has been disrupting these misrepresentations.

For the first research question, the findings of this study suggest that Somali artists allow their art to interact with all of their intersections, which in essence has allowed them to feel a sense of belonging not to society in general, but rather mainly to their Black Muslim community. All artists described their work mainly interacts with their Black and/or Muslim identities, but all of them consciously or subconsciously created their work in interaction with their Somali identities. The different levels of interaction with different intersections of one identity is interesting due to the similar contexts in which all of these young people are living; young adult Somali women artists who grew up as refugees or are the children of refugees. It raises questions that could be addressed in future research as to why young Somali women gravitate towards aligning with some of their identities and not others? Creating and sharing diaspora art for the young Somalis has been cited by most of the participants to be a means of healing, communication and community-building and none of the respondents associated their sense of belonging to the communities outside of the Black, Muslim and/or Somali community. There was a common underlying sense of belonging to the Somali community in all cases and all of the artists interacted with their Somali Canadian/American identity in some way through their art. There was also a common understanding that sense of belonging was rooted in being in 
connection with similar others with an understanding that that connection is built upon being able to both participate in and contribute to the communities in which they felt they belonged to.

In terms of the second question, Somali artists have been using social media, in most cases to disrupt the current negative narratives of their identities. Each of the respondents affirmed that their work did occupy the "in-between" space. The research revealed that Black Somali Muslim women who created art and shared it on social media have been integrating their Blackness, Somaliness and/or Muslimness into their work and in some cases, it reinforced thier sense of belonging to one or more of the communities. As young members of the diaspora, this meant that their art also interacted with their Western identities, where their work occupied a space of fusion of their Somalinimo and their Western identities while also navigating through topics of Blackness and Muslimness. Interestingly, all of the artists understood that there was negativity shared regarding their Black and Muslim identities via mass media but only some said these negative stories played a role in their artwork. As one of the respondents indicated, disrupting mainstream narratives is inevitable when sharing positive stories about the lived experiences of Black Muslim women in the West.

\section{Chapter 9: Recommendations and Further Studies}

Although this paper examines the sense of belonging for the young Somali diaspora in the West, due to the nature of the responses, it was limited to seeking a better understanding of their sense of belonging within their own communities rather than within the Canadian, American society at large. Where initially, this research aimed to explore a sense of belonging Somali's had within society in general, it became research geared towards better understanding of Somali's sense of belonging mainly within the Black and Muslim communities. The 
interactions each participant had with the rest of society was limited to the negative narratives shared by mainstream media and so, the research was not able to delve as deeply into how the media influences the marginalization of each of these communities. More specifically, due to the nature of existing academic literature, the research was unable to find enough information that corresponds with the sense of belonging for the Black Muslim community in the West, rather it had to rely on analyzing and cross-referencing information that exists on the Black community and the Muslim community separately.

A recommendation for potential research opportunities would be to delve further into the examination of the Black Muslim community in the West. There is a large gap where literature on Black communities and literature on Muslim communities can be tackled through the intersectional lens of the Black Muslim. The sense of belonging for children of refugees and forced migrants would also be an interesting stream of research to follow as the refugee body is one that deeply marginalized by mainstream media outlets. Should I pursue a PhD study, another recommendation I would be interested in pursuing would be to conduct a cross-analysis of diaspora artists from different diaspora communities and how their art is influenced by understandings of "home". 


\section{Appendices}

\section{A.1. - Consent Form}

\section{Ryerson University}

Ryerson University Consent Agreement

You are being invited to participate in a research study. Please read this consent form so that you understand what your participation will involve. Before you consent to participate, please ask any questions to be sure you understand what your participation will involve.

Title of the Study

Young Diaspora Somali Women's Navigation of Intersectional Identities

In Online Social Media Spaces

\section{INVESTIGATORS}

This research study is being conducted by Samira Warsame, a graduate student in the MA Immigration and Settlement Studies program at Ryerson University.

If you have any questions or concerns about the research, please feel free to contact;

Samira Warsame at samira.warsame@ ryerson.ca; or the Research Supervisor Dr. Amina Jamal at amina.jamal@ ryerson.ca

\section{PURPOSE OF THE STUDY}

This study will explore how Somali women engage with their identities through arts via social media outlets. It will examine whether or not they feel they are providing an alternative narrative to the stereotypical Somali, Black, Muslim and diaspora narratives. It will also inquire about the motivations for doing so.

From semi-structured interviews conducted with 6 to 8 Somali women from the arts communities in both Toronto, Ontario and Minneapolis, Minnesota, this work will explore the artistic exploration of their identities through the use of social media outlets. To be eligible for this study, you must be;

- A Self-Identifying Somali Woman in Toronto, ON or Minneapolis, MN.

- Visual artists whose work centers culture, race, religion, identity, and/or belonging;

- Publically sharing your work on either Instagram or Twitter

This research will contribute to the findings of a Major Research Paper (MRP).

\section{WHAT YOU WILL BE ASKED TO DO [OR] WHAT PARTICIPATION MEANS}

If you volunteer to participate in this study, you will be asked to do the following things: $\underline{\text { Interview }}$

- $\quad$ Signing this consent form for participation in this study

- Agree to a 60 minute one-on-one interview in a private location in downtown Toronto (ie. booked Ryerson study room)

- Respond to in-depth questions regarding intentions behind art creation and dissemination via social media

- Ie. What is your art medium? What story are you telling with your art? In what ways does your art interact in issues around religion, culture, identity, intersectionality, race or gender?

Demographic Data

- Age, Ethnicity and Gender/Sex will be the only demographic data collected for research purposes. 
Research Findings will be available to participants via email once MRP is completed. Please leave your email if you would like to receive a link to Ryerson's online repository for MRP's for full access to the final research findings of this study.

Email address:

\section{POTENTIAL BENEFITS}

This study will provide new information in regards to the Somali community in Toronto and Minneapolis. Diaspora arts research in academia is also a rare find and this type of research being conducted within the Somali community will provide a substantial amount of new information for the academic community.

I cannot guarantee, however, that you will receive any personal benefits from participating in this study.

\section{WHAT ARE THE POTENTIAL RISKS TO YOU AS A PARTICIPANT}

The potential risks are very low. You will be asked whether you want to use a pseudonym (nickname) or their real names for the research. Should you choose to use a pseudonym, the risks are associated with information collected from your interview that may be identifiable with you. To avoid this risk, you will be provided with the option to opt out of the research if you would rather not provide any information that may be too personal in relation to your artwork.

\section{CONFIDENTIALITY AND DATA STORAGE}

Pseudonyms will be assigned to all participants who wish to not be identified by name. All information (ie. transcripts, audio files, etc.) will be confidential and kept on a password protected Ryerson Google Drive. It will solely be shared with the research supervisor, Professor Amina Jamal. With your consent, interviews will be audio-recorded and then written out by Samira Warsame. All audio-recordings will be destroyed upon completion of transcription (writing out the recording word-for-word).

This online storage of information will be kept until the study is complete (September, 2019), and will be destroyed upon completion. Your personal responses will not be shared with other participants. You have the right to choose to not be audio-recorded. Participants have the right to review or edit the transcripts.

\section{VOLUNTARY PARTICIPATION AND WITHDRAWAL}

Participation in this study is completely voluntary. You can choose whether to be in this study or not. If any question makes you uncomfortable, you can skip that question. Your withdrawal from this study will not influence future relations with the researchers or Ryerson University. You may stop participating at any time. If you choose to stop participating, you may also choose to not have your data included in the study. Your choice of whether or not to participate will not influence your future relations with Ryerson University [and/or other institutions/partners of the research] or the investigator, Samira Warsame, involved in the research. You may fully withdraw your responses up until August 15th, which is when final research paper will be submitted.

\section{QUESTIONS ABOUT THE STUDY}

If you have any questions or concerns about the research now or in the future, please feel free to contact;

Samira Warsame at samira.warsame@ryerson.ca; or the Research Supervisor Amina Jamal at amina.jamal@ ryerson.ca

This study has been reviewed by the Ryerson University Research Ethics Board. If you have questions regarding your rights as a participant in this study, please contact:

Research Ethics Board c/o Office of the Vice President, Research and Innovation Ryerson University 350 Victoria Street

Toronto, ON M5B 2K3 416-979-5042 rebchair@ ryerson.ca

Young Diasporic Somali Women's Navigation Of Intersectional Identities In Online Social Media Spaces

\section{CONFIRMATION OF AGREEMENT}

Your signature below indicates that you have read the information in this agreement and have had a chance to ask any questions you have about the study. Your signature also indicates that you agree to participate in the study and have been told that you can 
change your mind and withdraw your consent to participate at any time. You have been given a copy of this agreement. You have been told that by signing this consent agreement you are not giving up any of your legal rights.

Name of Participant (please print)

Signature of Participant

Date

Please read the following and check the ONE box that applies.

I agree to have a pseudonym or nickname used in the place of my real name for privacy purposes in this study.

I agree to have my real name used in this study.

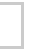

Signature of Participant

Date

I agree to be [audio-recorded] for the purposes of this study. I understand how these recordings will be stored and destroyed.

Signature of Participant

Date 


\section{A.2. - Recruitment Poster}

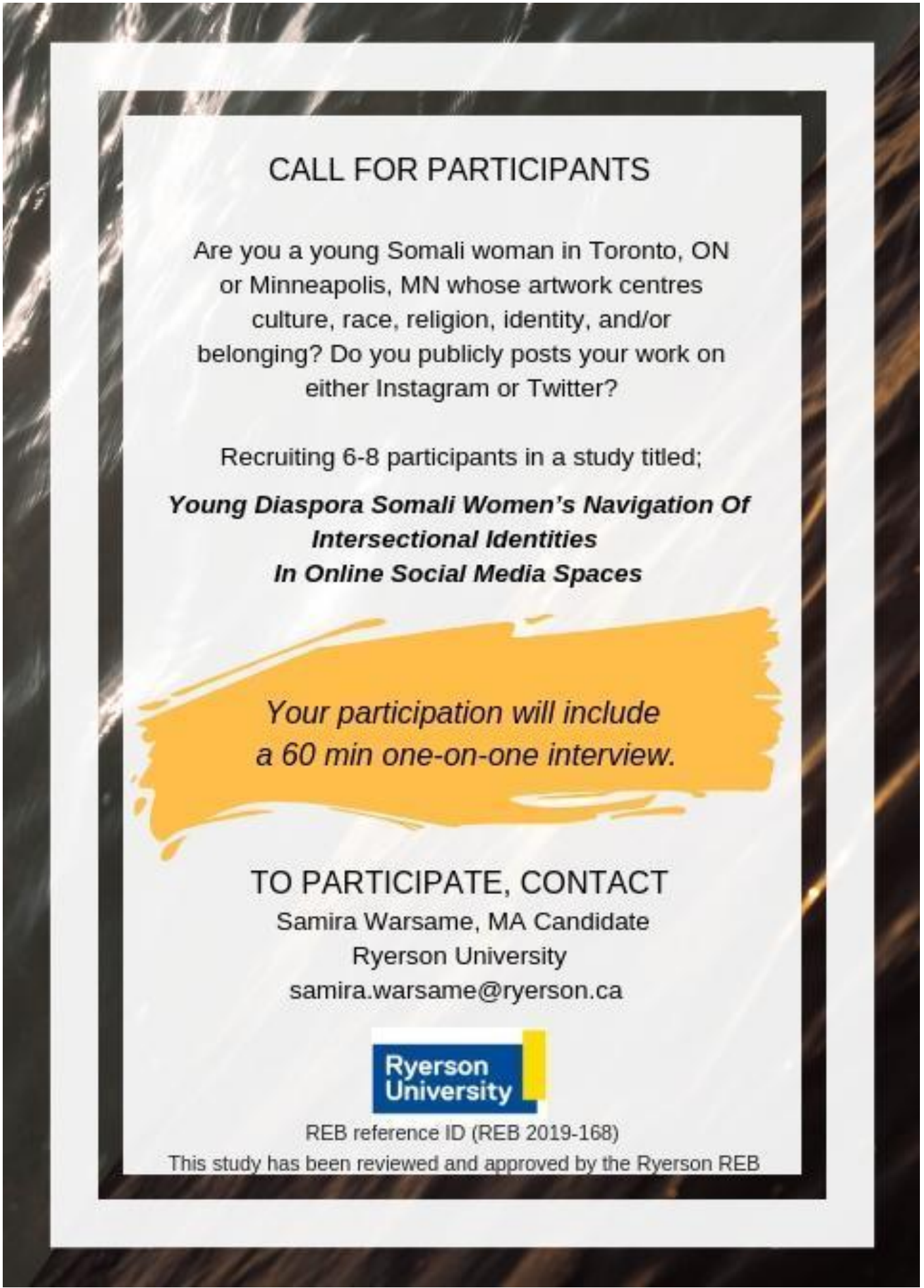




\section{A.3. - Interview Guide}

The following questions were used to guide the interviews;

1. What communities or identities do you feel like belong to?

2. What is your understanding of narratives disseminated via mass media about women you identify with? Ie. Black/Muslim/Immigrant/Refugee/Diaspora women.

3. What role do you think user-created (social media) content has in the reshaping of mass media narratives?

4. What were your intentions when you began your artistic journey?

5. Your art seems to interact deeply with your cultural roots, what are your intentions while expressing pieces of yourself "here" and "there"?

6. Did mainstream media narratives play a role in your journey?

7. How are you using social media to challenge/disrupt these racist, discriminatory, islamophobic, etc, narratives?

8. Does intersectionality have a role in your art creation process? 


\section{References}

Abdul Khabeer, S. (2016). Muslim Cool. New York University Press. New York.

Appiah, O. (2002). Black and White Viewers Perception and Recall of Occupational Characters on Television. Journal of Communication, 52(4), 776-793.

doi:10.1111/j.1460-2466.2002.tb02573.x

Bergeron, P. (2018, October 24). Quebec Wants To Ban Civil Servants From Wearing Burka And Niqab. Retrieved from https://www.huffingtonpost.ca/2018/10/24/quebecburka-niqab-chador-ban_a_23570832/

Berns-McGown, R. (1999). Somalis and Identity - Muslims in the Diaspora. Toronto: University of Toronto Press, Scholarly Publishing Division.

Bhatia, S., \& Ram, A. (2001). Rethinking 'Acculturation' in Relation to Diasporic Cultures and Postcolonial Identities. Human Development, 44(1), 1-18. doi:10.1159/000057036

Bhabha, H. K. (1994). The Location of Culture. London and New York: Routledge.

Bochner, E. (2003). An Introduction to the Arts and Narrative Research. Qualitative Inquiry. Sage Publications. 9(4). 506-515

Césaire, A. (1972). Discourse on colonialism: Translated by Joan Pinkham. New York: Monthly Review Press.

Chávez, A. F., \& Guido-Dibrito, F. (1999). Racial and Ethnic Identity and Development. New Directions for Adult and Continuing Education, 1999(84), 39-47.

doi:10.1002/ace.8405

Cheers, I. M. (2018). The evolution of black women in television mammies, matriarchs and mistresses. New York and London: Routledge.

Collins, P. H. (2012). Social Inequality, Power, and Politics. The Journal of Speculative Philosophy, 26(2), 147-162. doi:10.1093/acprof:oso/9780190459239.003.0009

Collins, P. H., \& Bilge, S. (2018). Intersectionality. Cambridge, United Kingdom: Polity Press.

Collins, P. H. (2015). Intersectionality's Definitional Dilemmas. Annual Review of Sociology,41(1), 1-20. doi:10.1146/annurev-soc-073014-112142

Crenshaw, K. (1991). Mapping the Margins: Intersectionality, Identity Politics, and Violence against Women of Color. Stanford Law Review, 43(6), 1241. doi:10.2307/1229039 
Crenshaw, K. (2016). The Urgency of Intersectionality. TedTalks Women. Retrieved from https://www.ted.com/talks/kimberle_crenshaw the_urgency_of_intersectionality/upnext?language $=$ en

Crichlow, W. (2015). Critical Race Theory: a Strategy for Framing Discussions Around Social Justice and Democratic Education. Higher Education in Transformation Conference.

Davies, C. B. (2002). Black women, writing and identity: Migrations of the subject. London: Routledge.

Everett, A. (2009). Digital Diaspora - a Race for CyberSpace. SUNY Press.

Fergusson, J., \& Razack, S. H. (2004). Dark Threats and White Knights: The Somalia Affair, Peacekeeping, and the New Imperialism. International Journal, 59(4), 971.

doi:10.2307/40203999

Finn, R. L. (2011). Surveillant staring: Race and the everyday surveillance of South Asian women after 9/11. Surveillance \& Society, 8(4), 413-426. doi:10.24908/ss.v8i4.4179

Foot, R. (2018). Somalia Affair. Retrieved from

https://www.thecanadianencyclopedia.ca/en/article/somalia-affair

Gembus, M.P. (2016) The safe spaces ‘in-between’ - plays, performance and identity among young 'second generation' Somalis in London, Children's Geographies, 16:4, 432443, DOI: $\underline{10.1080 / 14733285.2017 .1362498}$

Goldman, A. Y., Hopson, M., Ford, V., Harris, A., Howard, N., \& Boylord, R. (2014). Black women and popular culture the conversation continues. Lanham, MD: Lexington Books.

Guest, G., MacQueen, K. M., \& Namey, E. E. (2012). Applied thematic analysis. Los Angeles: Sage Publications.

Hall, S. (1992). The West and The Rest; Discourse and Power. Race and Racialization, 85-9

Hall, S. (1996) The question of Cultural Identity. Modernity An Introduction to Modern Societies. Blackwell Publishers.

Isaacs, H. R. (1994). Idols of the tribe group identity and political change. Cambridge, Mass.: Harvard University. Pr, 31-35

Jiwani, Y. (2018). Doubling discourses and the veiled Other: Mediations of race and gender in Canadian media. Race and Racialization. 
Kabir, N. A. (2014). Young Somalis in Australia, the UK and the USA: An Understanding of Their Identity and their Sense of Belonging. Journal of Muslim Minority Affairs, 34(3), 259-281. doi:10.1080/13602004.2014.939556

Karim, H. (2006). The Media of Diaspora: Mapping the Globe. Erscheinungsort nicht ermittelbar: Routledge.

Kavakci, E., \& Kraeplin, C. R. (2016). Religious beings in fashionable bodies: The online identity construction of hijabi social media personalities. Media, Culture \& Society, 39(6), 850-868. doi:10.1177/0163443716679031

Khan, S. (1998). Muslim Women: Negotiations in the Third Space. Signs: Journal of Women in Culture and Society, 23(2), 463-494. doi:10.1086/495259

King, T. (2011). The Truth About Stories: a Native Narrative. New York: House of Anansi Press.

Knowles, J. G., \& Cole, A. L. (2008). Handbook of the arts in qualitative research perspectives, methodologies, examples, and issues. Los Angeles: Sage Publications.

Kumsa, M. K. (2006). Between Home \& Exile: Dynamics of negotiating belonging among Oromos living in Toronto. The African Diaspora in Canada, 175-204.

doi:10.2307/j.ctv6gqw99.14

Legislative Services Branch. (2019, June 04). Canadian Multiculturalism Act. Consolidated Federal Laws of Canada. Retrieved from https://laws-lois.justice.gc.ca/eng/acts/c-18.7/page$\underline{1 . h t m l}$

Longhurst, R. (2016). Semi-Structured Interviews and Focus Groups. Key Methods in Geography. Sage Publications LTD.

Mainsah, H. (2014). Young African Norwegian women and diaspora: Negotiating identity and community through digital social networks. Crossings: Journal of Migration \& Culture, 5(1), 105-119. doi:10.1386/cjmc.5.1.105_1

McMillan, J. H., \& Wergin, J. F. (2002). Understanding and Evaluating Educational Research. Upper Saddle River: Merrill Prentice Hall.

McMurray, A. (2007). Hotep and Hip-Hop: Can Black Muslim Women Be Down with Hip-Hop? Meridians: Feminism, Race, Transnationalism, 8(1), 74-92. doi:10.2979/mer.2007.8.1.74 
Midden, E., \& Ponzanesi, S. (2013). Digital faiths: An analysis of the online practices of Muslim women in the Netherlands. Womens Studies International Forum, 41, 197-203. doi:10.1016/j.wsif.2013.07.012

Miller, J. (1994, May). Policy change renews hopes of rejected refugee claimants. Ottawa Citizen.

Mirza, H. S. (2013). 'A second skin': Embodied intersectionality, transnationalism and narratives of identity and belonging among Muslim women in Britain. Womens Studies International Forum, 36, 5-15. doi:10.1016/j.wsif.2012.10.012

Moghissi, H., \& Ghorashi, H. (2016). Muslim diaspora in the West: Negotiating gender, home and belonging. London: Routledge, Taylor et Francis Group.

Mohamed, H. A. (2017). The triple consciousness of black Muslim women : The experiences of first generation Somali-Canadian women activists. Journal of Somali Studies, 4(1/2), 9-42. doi:10.31920/2056-5682/2017/v4n1_2a1

Mohamud, A. F. (2017). The Somali-Diaspora Experience: A Focus on Somali Children as Cultural Brokers and as Ambassadors Of Language And Culture. Ryerson University.

Neuman, W. L. (2011). Social research methods: Quantitative and qualitative approaches. New Delhi: Pearson.

Puplampu, K. P., \& Tettey, W. J. (2006). Border Crossings \& Home-Diaspora Linkages Among African-Canadians:. The African Diaspora in Canada, 149-174.

doi:10.2307/j.ctv6gqw99.13

Richardson-Stovall, J. (2012). Image Slavery and Mass-Media Pollution: Popular Media, Beauty, and the Lives of Black Women. Berkeley Journal of Sociology, 56, 73-100.

Retrieved from https://search-proquestcom.ezproxy.lib.ryerson.ca/docview/1019966013?pq-origsite=summon

Said, E. W. (1991). Orientalism. London: Penguin.

Savin-Baden, M., \& Wimpenny, K. (2014). A Practical Guide to Arts-related Research. Rotterdam: Sense

Scuzzarello, S. (2013). Narratives and Social Identity Formation Among Somalis and Post-Enlargement Poles. Political Psychology, 36(2), 181-198. doi:10.1111/pops.12071 
Shephard, T. (2018, January 19). Most Somali-speaking Torontonians live in Etobicoke, census shows. Etobicoke Guardian. Retrieved from https://www.toronto.com/communitystory/8046115-most-somali-speaking-torontonians-live-in-etobicoke-census-shows/

Smith, D. E. (1987). The Everyday World as Problematic: A Feminist Sociology. Toronto: University of Toronto Press.

Sobande, F., Fearfull, A., \& Brownlie, D. (2018). Resisting media marginalisation: Black women's digital content and collectivity. Consumption Markets \& Culture, 1-16. doi:10.1080/10253866.2019.1571491

Swisher, S. (2019). Gendered Islamophobia and Sense of Belonging: Experiences of Visibly Muslim Women in Higher Education. ProQuest Dissertations.

Tettey, W. J., \& Puplampu, K. P. (2006). The African Diaspora in Canada: Negotiating Identity and Belonging. University of Calgary Press.

Tsui, A. O., Ragsdale, T. A., \& Shirwa, A. I. (1991). The settlement of Somali nomads. Genus. 131-152. Retrieved from https://www-jstororg.myaccess.library.utoronto.ca/stable/29789048?pqorigsite $=$ summon $\&$ seq $=1 \#$ metadata_info_tab_contents

Walcott, R. (2018). Black like who?: Writing Black Canada. London, Ontario: Insomniac Press.

Warren, S. (2018). Placing faith in creative labour: Muslim women and digital media work in Britain. Geoforum, 97, 1-9. doi:10.1016/j.geoforum.2018.10.003

Williams, S. (2015). Digital Defense: Black Feminists Resist Violence With Hashtag Activism. Feminist Media Studies, 15(2), 341-344. doi:10.1080/14680777.2015.1008744

Zine, J. (2006). Unveiled Sentiments: Gendered Islamophobia and Experiences of Veiling among Muslim Girls in a Canadian Islamic School. Equity \& Excellence in Education,39(3), 239-252. doi:10.1080/10665680600788503 